\title{
On the ballistic wave from projectiles and vehicles of simple geometry
}

\author{
Jean Varnier*, Marie-Claire Le Pape ${ }^{\circ}$ \\ ONERA, 92320 Châtillon, France \\ Frédéric Sourgen ${ }^{\circ}$ \\ ONERA, 31400 Toulouse, France
}

The ballistic wave is a shock wave generated by a solid body moving at supersonic speed in the atmosphere. It sounds like the crack of a whip for small projectiles, like a detonation (sonic boom) for large-sized objects. Their common signature is a N-shaped pressure profile, the formalism of which is well-known but presents a practical difficulty, namely the calculation of the "shape factor" which characterizes the aerodynamic behavior of the object flying at supersonic speed. In the present paper, we present that calculation for simple geometric shapes defined by their algebraic equations, by using both numerical and analytical approaches. The results do not seem realistic in some cases of round-tipped shapes, what leads us to adopt, in general, a simplified form for the shape factor, different from that which is sometimes used in the literature. On the other hand, such an approach suggests to us to take into account separately the ogival length and the overall length of the body. In order to compare classic and improved models, examples of ballistic wave calculation are given for some bullets and small-caliber shells whose shape is roughly defined. Finally, it appears interesting to test these models on a larger scale by simulating the sonic boom of the Apollo Command Module during its atmospheric reentry and the sonic boom of the F104 Starfighter in horizontal flight. The results obtained seem to justify the improvements proposed for the theoretical model of ballistic wave and sonic boom arising from flying objects of simple geometry.

$\begin{array}{ll}a & \text { Parameter } \\ a_{i} & \text { Slope } \\ b & \text { Parameter } \\ c & \text { Sound speed, } \mathrm{m} / \mathrm{s} \\ D & \text { Diameter, } \mathrm{m} \\ F & \text { Whitham's function } \\ F_{W} & \text { Shape factor } \\ h & \text { Height or step in abscissa } \\ H & \text { Length of ogival part, } \mathrm{m} \\ i & \text { Number of a step (subscript) } \\ I_{W} & \text { Whitham's integral } \\ k & \text { Scale factor } \\ k_{L} & \text { Lift coefficient } \\ k_{S} & \text { Shape coefficient } \\ K_{\Delta T} & \text { Factor for wave period } \\ L & \text { Overall length, m } \\ m & \text { Parameter } \\ M & \text { Mach number } \\ n & \text { Total number of steps } \\ P & \text { Pressure, Pa } \\ \Delta P & \text { N-wave amplitude, Pa or psf }\end{array}$

\section{Nomenclature}

$\begin{array}{ll}r & \text { Distance to trajectory, m or yd } \\ R & \text { Radius, } \mathrm{m} \\ s & \text { Integration variable } \\ S & \text { Cross section, } \mathrm{m}^{2} \\ t & \text { Time, } \mathrm{s} \\ \Delta T & \text { N-wave period, } \mathrm{s} \\ u & \text { Integration variable } \\ V & \text { Velocity, } \mathrm{m} / \mathrm{s} \\ x & \text { Abscissa } \\ y & \text { Ordinate } \\ z & \text { Altitude, } \mathrm{m} \\ \alpha & \text { Half-angle of aperture } \\ \beta & \text { Slope of tip (tan } \alpha \text { ) } \\ \gamma & \text { Ratio of specific heats } \\ \delta & \text { Thickness ratio } \\ \varepsilon & \text { Slope or small number } \\ \theta & \text { Temperature, }{ }^{\circ} \text { Celsius } \\ \sigma & \text { Standard deviation } \\ O & \text { Ambient or surface data (subscript) }\end{array}$

* Research Engineer, Department DAAC (Aeroacoustics), jeanvarnier@outlook.fr

- Research Engineer, Department DMFN (Fluid Mechanics), marie-claire.le_pape @onera.fr

${ }^{\circ}$ Research Engineer, Department DMAE (Aerothermodynamics), frederic.sourgen@ onera.fr 


\section{Introduction}

$\mathrm{T}$ HE "ballistic wave" generated by a projectile moving at supersonic speed sounds like the crack of a whip when the projectile is passing by. It was the topic of experimental studies carried out at the end of $19^{\text {th }}$ Century and especially at the beginning of $20^{\text {th }}$ Century [1-4]. A semi-empirical theory enabling to calculate the shock waves from firearm bullets was developed during and after World War II [5-9]. The critical points concern the near-field aerodynamic behavior related to the shape of the projectile, and the propagation of the ballistic wave in mid-field and far-field, knowing that the formalism used must take into account nonlinear effects, the influence of which varies according to the distance to the flight path [10-15]. The interest in the ballistic wave has been renewed recently for the operational detection of small-caliber projectiles [16-19].

The theory developed for projectiles of simple shape (symmetry of revolution) has then been extended to supersonic aircraft, by taking into account the lift effects and the theoretical problems relating to the propagation of the "sonic boom" through the atmosphere as far as the observer location [20-29]. Thus, the sonic boom is the detonation resulting from a ballistic wave of high amplitude.

It was of course important to collect experimental data to validate the physical and numerical models aiming at predicting amplitude and duration of the sonic boom perceived at the ground level in a given case [30-37]. For instance, the cruise flight conditions of the French-British supersonic airliner Concorde (Mach 2, 17,000 m height) are well adapted for such studies [38-39]. In contrast, the operating flight conditions of the USAF's strategic reconnaissance plane SR-71 Blackbird (Mach 3, 26,000 m height) are at the limit of the validity domain of the theory. For this reason, the sonic boom generated by objects flying at hypersonic velocity at high altitude was the subject of specific studies [40-49]. The recent orientations concern the minimization of the sonic boom perceived at ground level by suitable aircraft geometry and flight trajectory on the one hand [50-54], the generalization of the computational fluid dynamics (CFD) to replace the analytical models on the other hand [5560]. For a long time limited to the calculation of the aerodynamic field close to the supersonic object, the CFD now tends to increase its spatial range, thanks to the use of adaptive meshes, for instance.

In order to apply Whitham's theory, we are interested in a first step by the "historical" case of firearm projectiles. A practical difficulty concerns the calculation of the "shape factor" which characterizes the aerodynamic behavior of a body moving at supersonic speed. Numerical and analytical solutions are proposed to solve this problem for some curvatures of the ogival part (curved part) of the body defined by their algebraic equations. Calculations are made for both pointed and round-tipped shapes, the latter case revealing an apparent gap of the theory, since some values of the shape factor appear clearly unrealistic.

Finally, this study not only leads us to modify a formula suggested or implicitly used in the literature [9,13,16-17], but also highlights the need for taking into account the ogival part, and the cylindrical part of the projectile separately. As a result, a contribution of this work is the calculation of two distinct shape factors for the amplitude and for the duration (or period) of the ballistic wave. The improved model is then tested by referring to the original model and to real data from experiments carried out by the US Army and by the French Air Force with bullets and small-caliber shells.

Both models are then applied to a large-scale phenomenon, namely the sonic boom from the Apollo Command Module recorded at sea level during the atmospheric reentry of the flights Apollo 15 and Apollo 16 over the Pacific Ocean [41-42]. In order to test the validity of the physics of continuous media for the flight points located at very high altitude, a preliminary study was carried out with the help of a fluid dynamics computer code. Finally, the results of the semi-empirical analytical models seem to confirm the need to take into account the general shape of the body more accurately than the classic theory, and seem to validate the changes made at least in the case of the blunt and compact shape considered.

It was therefore necessary to confirm this result from simulations concerning pointed and elongated flying objects more in line with the usual field of application of Whitham's theory. Apart from a purely numerical application to a rocket body, it seemed appropriate to apply the models (including the well-known "first-cut method" [23-24]) to the sonic boom of the F-104 Starfighter, a fighter whose profile is relatively close to that of a body of revolution. The conclusions are identical to the previous ones and seem to confirm, in the first analysis, the validity of the simple calculation method that is proposed to define the parameters of the ballistic wave.

\section{Ballistic wave of a projectile}

\section{A. Theory}

For human hearing, the ballistic wave generated in the atmosphere by a body such as a rifle bullet moving at supersonic speed (Fig. 1) is perceived as a sharp snap similar to the crack of a whip when the projectile is passing by. This crack corresponds to a shock wave bordered with a sudden overpressure in front of the wave and a sudden under-pressure at its rear part (Fig. 2, on the right), hence the generic name "N-wave" given to the 
time signal (Fig. 2, on the left). This profile can be characterized by two parameters: overpressure or amplitude $\Delta P$ and overtaking duration or wave period $\Delta T$. Their values at a given distance from the projectile path can be calculated with the help of well-known formulas [8-9]. Dimensions and shape of the projectile are introduced by Whitham's function (also called "F-function" in the literature):

$$
F_{(s)}=\frac{1}{2 \pi} \int_{0}^{s} \frac{S^{\prime \prime}{ }_{(x)}}{\sqrt{s-x}} d x
$$

where $S_{(x)}$ is the cross-section of the body at abscissa $x$ (Fig. 3) and $S^{\prime \prime}{ }_{(x)}$ its second derivative, $s$ being an integration variable. The integral $I_{W}$ of this function, that we call Whitham's integral, is then written:

$$
I_{W}=\int_{0}^{L} F_{(s)} d s=\int_{0}^{L} d s \frac{1}{2 \pi} \int_{0}^{s} \frac{S^{\prime \prime}(x)}{\sqrt{s-x}} d x
$$

where $L$ is the total length of the body. Its square root $F_{W}$, so-called "shape factor" [9]:

$$
F_{W}=\left[I_{W}\right]^{1 / 2}
$$

is used in order to calculate the parameters of the $\mathrm{N}$-wave. We have in particular for the amplitude $\Delta P$ :

$$
\frac{\Delta P}{P_{0}}=2^{1 / 4} \gamma(\gamma+1)^{-1 / 2}\left(M^{2}-1\right)^{1 / 8} F_{W} r^{-3 / 4}
$$

where $P_{0}$ is the ambient pressure, $\gamma$ is the ratio of the specific heats of the air, $M$ is the Mach number $V / c_{0}$ of the flying object and $r$ is the normal distance from the observer to the trajectory (so called miss-distance in Ref. $[6,15])$.

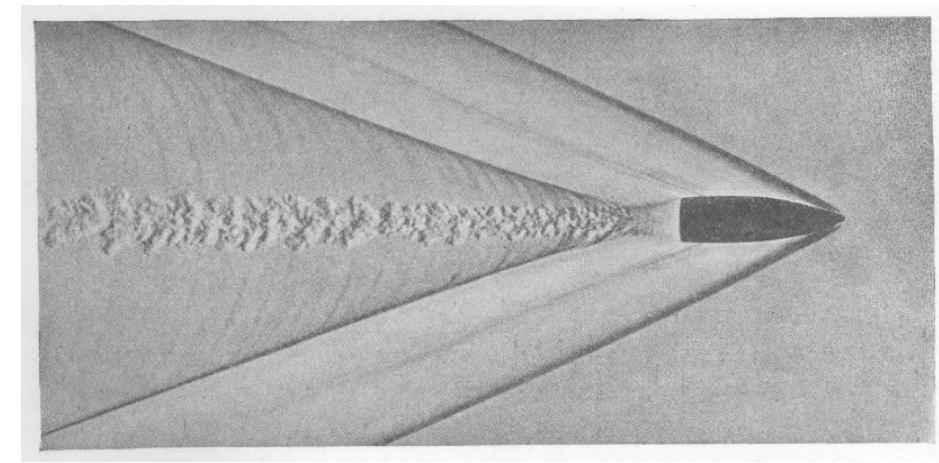

Fig. 1 Shock wake from a rifle bullet (from Ref. [2]).

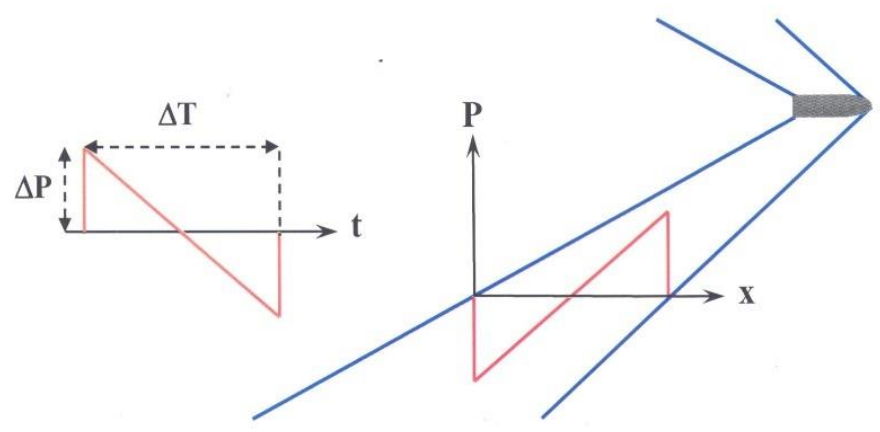

Fig. 2 Time profile and space profile of the $\mathrm{N}$-wave.

In Ref. [16-17] dealing with small bullets, Eq. (4) is replaced by the following formula:

$$
\frac{\Delta P}{P_{0}}=0.53\left(M^{2}-1\right)^{1 / 8} \frac{D}{\mathrm{~L}^{1 / 4}} r^{-3 / 4}
$$


where $D$ and $L$ are the projectile diameter and the projectile length respectively. By comparing Eq. (4) and (5) and by introducing the radius $R=D / 2$ in Eq. 5, we find the implicit identity for the shape factor:

$$
F_{W}=\frac{R}{L^{1 / 4}}
$$

The authors refer to Ref. [8-9], but in fact such a relation is only suggested in Ref. [9] (p. 318) without any demonstration for "slender bodies" of overall length $L$ including or not a cylindrical part. Ref. [13] (p. 336) is not much more explicit in stating the following expressions for the shape factor of a small projectile in far-field:

$$
\begin{aligned}
& F_{W} \propto \delta L^{3 / 4} \\
& \delta=D / L
\end{aligned}
$$

$\delta$ being the "thickness ratio" of the projectile. In an example given for a shape including an ogival part and a cylindrical part (see Fig. 3), this ratio is taken equal to 0.2 as a usual value for standard bullets or shells. Let us note that an immediate consequence of Eq. (1) is that Whitham's function and therefore the shape factor are equal to zero for the cylindrical part of a body, since the derivatives $\mathrm{S}_{(x)}{ }_{(x)}$ and $S^{\prime \prime}{ }_{(x)}$ of a constant cross section $\mathrm{S}_{(x)}$ are already zero.

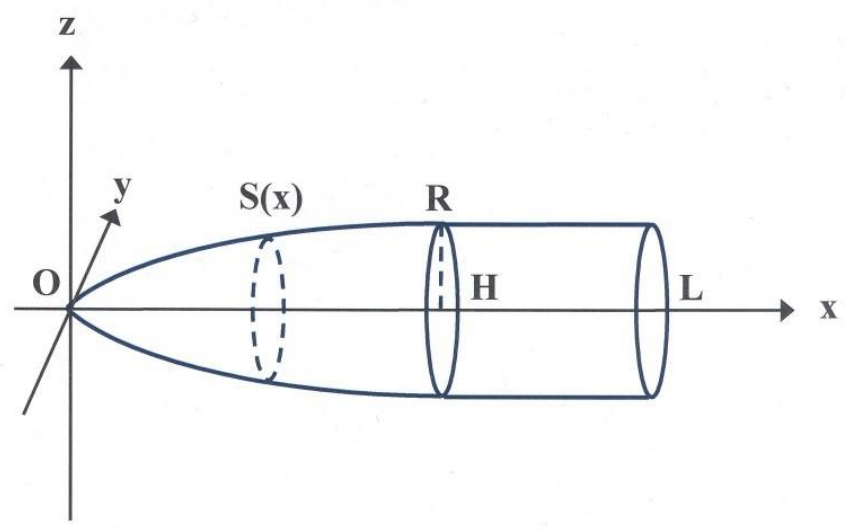

Fig. 3 Geometry of a projectile and related notations.

Otherwise, in Whitham's formalism, the duration or period $\Delta T$ of the $\mathrm{N}$-wave is given by the equation:

$$
\Delta T=2^{5 / 4} \frac{(\gamma+1)^{1 / 2}}{c_{0}} M\left(M^{2}-1\right)^{-3 / 8} F_{W} r^{1 / 4}
$$

where $c_{0}$ is the sound speed at the ambient conditions. This expression is obtained by dividing by the speed $V$ that of the wavelength $\Delta \lambda$ given in Ref. [9]. The shape factor $F_{W}$ being the same as in Eq. (4), Eq. (6) suggests that the overtaking duration $\Delta T$ of the wave will decrease if the projectile length $L$ increases, which seems illogical from the point of view of physics, since the projectile cap is clearly involved in the formation of the rear shock wave. It is perhaps for this reason that the shape factor is given in Ref. [13] under the unusual form of Eq. (7). Note that the ratio $\Delta P / \Delta T$ of Eq. (4) and (8) removes the common factor $F_{W}$ and therefore does not depend on the geometry of the projectile. After simplification, we have indeed:

$$
\frac{\Delta P}{\Delta T}=\frac{P_{0} c_{0}}{2} \frac{\gamma}{(\gamma+1)} \sqrt{1-\frac{1}{M^{2}}} r^{-1}
$$

This relationship, rarely quoted in the literature, may be interesting to detect anomalies such as sound reflections in experimental data.

Concerning Whitham's F-function of Eq. (1), it should be noted that other functions are sometimes used in the literature to characterize the shape of a body from the point of view of aerodynamics, namely the F-functions of Stieltjes and Lighthill [7,15,29]. According to Ref. [15], Lighthill's F-function gives better results than Whitham's one, especially in the case of complex shapes including slope discontinuities. 


\section{B. Calculation of the shape factor}

The literature rarely deals with the calculation of the shape factor $F_{W}$ that appears in Eq. (4) and (8). For instance, a "slender body" quoted in Ref. [9,13] and reminded in Ref. [28] is defined by:

$$
\begin{array}{lc}
R_{(x)}=0.1\left\lfloor 1-(1-x)^{3}\right\rfloor & 0 \leq x \leq 1 \\
R_{(x)}=0.1 & 1<x
\end{array}
$$

By referring to the symbols of Fig. 3, we have a maximum radius $R=0.1$, an ogival length $H=1$ and an undefined overall length $L$. For this shape, Ref. [13] indicates the "shape factor" $F_{W} \approx 0.104$ without other detail about the calculation, while the value $F_{W} \approx 0.095$ can be deduced from a numerical result given in Ref. [28]. In fact, the system made up of Eq. (1) to (3) has here an analytical result, namely $F_{W}=0.1$ sqrt $(36 / 55) \approx 0.081$ ("third degree shape" in Appendix A). Of course, the cylindrical part of the body beyond abscissa $x=1$ does not intervene in the result.

In general, the analytical calculations of the shape factor for ogival shapes defined by simple algebraic equations result in the term $\mathrm{R} / \mathrm{H}^{1 / 4}$ (see Appendix A), as already suggested by Eq. (6) and (7), except the fact that the length $\mathrm{H}$ of the ogival part stands in for the overall length $\mathrm{L}$ of the body. More generally, the shape factor can be written under the form:

$$
F_{W}=k_{S} \frac{R}{H^{1 / 4}}
$$

where $k_{s}$ is a dimensionless number that we call "shape coefficient". For instance, for a conical head of height $\mathrm{H}$ and of maximum radius $\mathrm{R}$, we obtain from Eq. (1) to (3):

$$
F_{W}=\sqrt{\frac{4}{3}} \frac{R}{H^{1 / 4}}
$$

that is a shape coefficient $k_{s} \approx 1.155$. This result is quoted in Ref. [15]. For the "third degree shape" defined by Eq. $(10)$ we obtain analytically $k_{s}=\operatorname{sqrt}(36 / 55) \approx 0.809$.

Other results for pointed shapes defined by their algebraic equations are given by original calculations in Appendix A. It appears that the shape coefficients of the chosen bodies are always within the range $1 \pm 0.2$.

Because numerous bullets, shells and rockets are in fact blunt or round-tipped, it is also interesting to test the formalism for this type of shape. However, it is pointed out in the literature [11,15] that the F-function must be equal to zero at the beginning - no aerodynamic source at the tip of the body. In practice, the problem that arises for blunt and round-tipped projectiles is bypassed by substituting a conical or polynomial shape for the nose [1415]. For the conic sections tested in Appendix B, it appears that the analytical shape coefficient may be close to one but also very small, zero or even imaginary. A borderline case concerns the parabolic shape, for which the shape coefficient $k_{S}$ is equal to 1 or 0 according to the analytical approach used (see $\S \mathrm{B} 1$ and B2 of Appendix B). To our knowledge, such calculations are ignored or in any case lacking throughout the literature on the subject.

In summary, the formalism appears inapplicable to the selected round-tipped shapes, at least from a physical point of view. This seems to confirm that the theory applies only to pointed bodies for which the shock wave is fastened to the tip, unlike round-tipped and blunt bodies for which the shock wave can be detached from the nose. Unfortunately, this purely physical interpretation of phenomena is probably not sufficient to explain the apparent failure of the theoretical model in the latter case, all the more so since some calculations results in Appendix B are quite plausible. In other words, the unrealistic results obtained elsewhere do not seem mathematically related to the rounded end of the profiles chosen, despite the singularity at the origin.

Finally, as suggested in Appendix B, it seems legitimate to assume that the real shape coefficients of such bodies are close to one in general, such as those of the pointed bodies. According to Ref. [11], the uncertainty admitted by neglecting the exact shape of a projectile for a given thickness ratio is of the order of $\pm 10 \%$, but Table A1 of Appendix A and Eq. (b13) of Appendix B rather suggest an uncertainty of $\pm 15 \%$. We can assume that this is as well the case for actual bullets or shells whose shape is difficult to know or to define precisely. Consequently and for lack of anything better, we will adopt $k_{s} \approx 1$ in the actual cases, hence the following expression of the shape factor:

$$
F_{W} \approx \frac{R}{H^{1 / 4}}
$$

where $R$ is the radius or half-caliber of the projectile and $H$ its ogival length. 
This equation looks like Eq. (6) but yet differs from it, since $H$ does not represent, in general, the overall length of the projectile. It may seem surprising that such an equation stemming directly from Whitham's formalism is apparently neither quoted nor used in the literature. A prosaic reason may be that the overall length of a projectile is easier to define than the length of its ogival part.

\section{Discussion}

The ballistic wave formalism suitable for standard firearm projectiles is a far-field approximation. Thus, the ratio $\Delta P / \Delta T$ of Eq. (9) does not depend on the shape of the projectile. Furthermore, equations such as Eq. (6) or Eq. (7) express that the $\mathrm{N}$-wave parameters $\Delta P$ and $\Delta T$ decrease as the projectile length $L$ increases, which seems questionable at least for the overtaking duration $\Delta T$, inevitably linked up with the cap effect. Formulas such as Eq. (11) to (13) that do not include the cylindrical length of the body seem somewhat preferable as regards the pressure amplitude $\Delta P$. On the other hand, it seems to be plausible that the total length of the body intervenes in the period $\Delta T$.

These remarks suggested to us to study numerically (see Appendix $\mathrm{C}, \S \mathrm{C} 1$ ):

- the influence of the scale factor for homothetic shapes on the one hand,

- the influence of the cylindrical length of a body whose ogival length remains unchanged on the other hand.

As a result, for a scale factor $k$, amplitude and period of the $\mathrm{N}$-wave vary according to a law in $k^{3 / 4}$, such as the formalism could predict it. When only the cylindrical length of the body varies, the ogival length being constant:

- the $\mathrm{N}$-wave amplitude $\Delta P$ remains almost constant,

- the N-wave period $\Delta T$ apparently varies according to a law in $L^{1 / 4}$.

Therefore, the shape factor given by Eq. (13) appears suitable for calculating the amplitude. In contrast, it shall be corrected for the period by the following factor:

$$
K_{\Delta T}=\frac{1}{2}\left(\frac{L}{R}\right)^{1 / 4}
$$

where $\mathrm{L}$ is the overall length and $\mathrm{R}$ the radius of the body. The factor $1 / 2$ has been set more or less empirically, assuming that $K_{\Delta T}=1$ (no correction) for a thickness ratio $D / L=1 / 8$ close to the one of Whitham's "slender body" [9].

Finally, we obtain the following shape factors for $\mathrm{N}$-wave amplitude and $\mathrm{N}$-wave period respectively:

$$
\begin{aligned}
& F_{W \Delta P}=\frac{R}{H^{1 / 4}} \\
& F_{W \Delta T}=\frac{1}{2}\left(\frac{L}{H}\right)^{I / 4} R^{3 / 4}
\end{aligned}
$$

Recall that these two shape factors implicitly include a shape coefficient $k_{s}$ taken equal to one for lack of anything better.

It should be noted that they are equal in the case of a slender body for which $L=8 D$, and not if the cylindrical length is zero $(H=L)$, which would correspond to a short body.

Equation (16) is yet subject to an objection: if the ratio $L / H$ and the radius remain constant, the elongation of the projectile no longer acts on the $\mathrm{N}$-wave duration. However, a constant period seems to be preferable to the decreasing period that results from Eq. (6). In fact, for a body of indefinite length, only the "half-period" determined by the first return at ambient pressure seems to have a precise duration [9,40]. That is the case for the sonic boom stemming from the launch vehicle Saturn V during its ascent over Atlantic Ocean [41-43], because of the presence of the large exhaust plume from the rocket engines. In any case, the theory will have to be further refined.

It is interesting to notice that Eq. (6), implicitly used in Ref. [16] for calculating the ballistic wave of bullets of $5.56 \mathrm{~mm}$ and $7.62 \mathrm{~mm}$ in caliber, gives quite satisfactory results. Eq. (16) and Eq. (6) are in fact equivalent if the following relationship is verified:

$$
8 H D \approx L^{2}
$$

what is true in particular for $H=2 D$ and $L=4 D$. These proportions are close to those of common bullets and small-caliber shells $(H=1$ to $3 D, L=3$ to $5 D)$. On the other hand, Eq. (15) and Eq. (6) give similar results when $H$ is close to $L$ because of the fourth root in denominator. That is why we test the two modes of calculation in the following experimental applications. 


\section{Experiments}

In order to verify the similarities pointed out above, we examined recent measurements [63], made with bullets of .30 inch caliber $(7.62 \mathrm{~mm}$ ) and shells of $30-\mathrm{mm}$ caliber in standard service in the French Air Force.

The 7.62-mm bullet used has a total length $L$ of $28.6 \mathrm{~mm}$ with an ogival length $H$ of circa $15.5 \mathrm{~mm}$. The 30$\mathrm{mm}$ shell has a total length of $107 \mathrm{~mm}$ with an ogival length of circa $53 \mathrm{~mm}$. The muzzle speed of both projectiles is close to $820 \mathrm{~m} / \mathrm{s}$. We consider here only the N-wave periods, the amplitudes being distorted by an unknown reflection coefficient. Note however that the theoretical ratio $\Delta P / \Delta T$ of Eq. (9) enables us to roughly estimate the value of this coefficient at about 1.7 to 1.8 , by assuming that the measured wave periods are reliable.

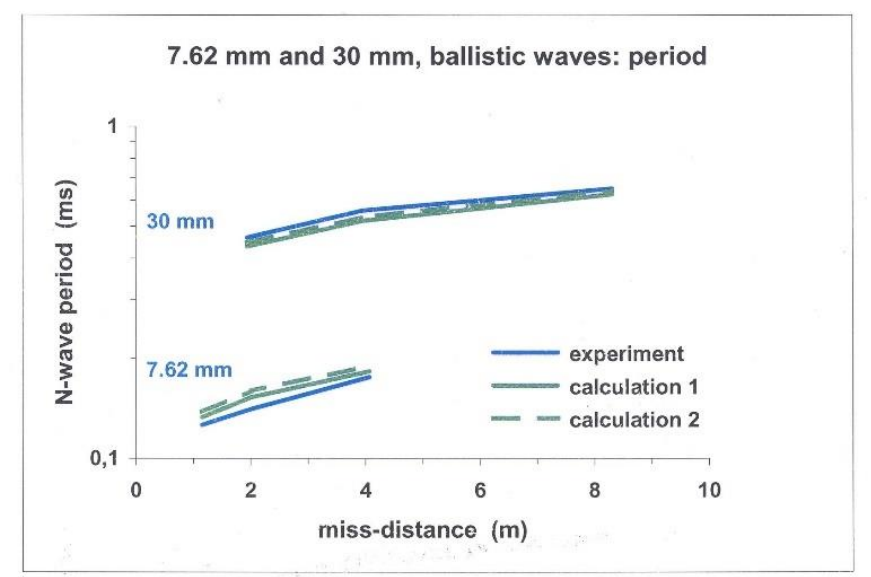

Fig. 4 Period of ballistic wave from 7.62-mm bullets and 30-mm shells.

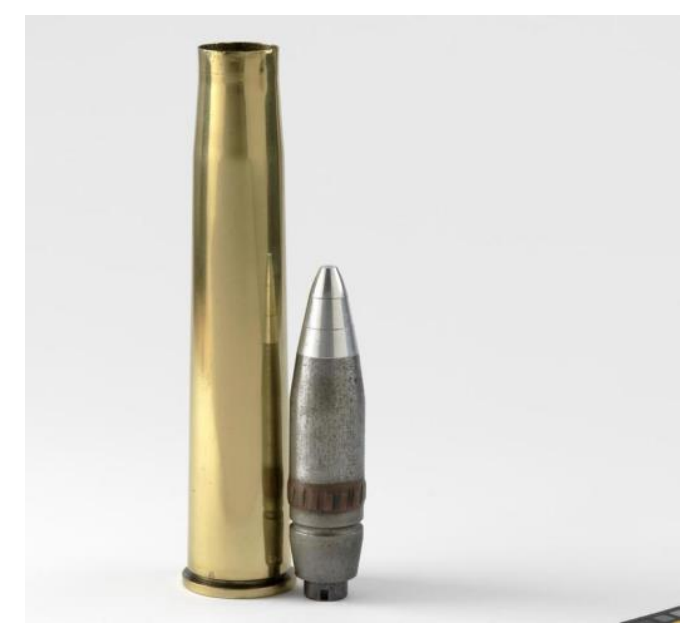

Fig. 5 Cartridge case and shell of a 40-mm Bofors gun.

For the simulations, we adopt by default a shape coefficient $k_{s}$ equal to one applied to Eq. (6), (15) and (16). In Fig. 4, the distances to the flight path of the projectiles, called miss-distances by analogy with the target shooting, appear fairly short. The curves "calculation 1" correspond to the shape factor given by Eq. (16) of the "improved model", the curves "calculation 2" correspond to the shape factor given by Eq. (6) of the "original model". The accuracy is around $10 \%$ for both calculations, with larger gaps for 7.62-mm caliber. Thus, it appears that the two formalisms are equivalent here.

We refer now to experiments performed at Camp Irwin, California, in November 1944. They provided the data used in Ref. [6]. Although dated, this work presents a reliable and relatively complete database concerning the light weapons. The following calibers were tested: $7.62 \mathrm{~mm}(.30$ inch), $12.7 \mathrm{~mm}(.50$ inch), $20 \mathrm{~mm}$ and 40 $\mathrm{mm}$. All these calibers were in standard service in the U.S. Army at that time. Complete test data are available for two calibers only, $12.7 \mathrm{~mm}$ and $40 \mathrm{~mm}$. The study of corresponding weapons led us to consider the probable use of the $.50 \mathrm{cal}$. Browning machine gun and of the $40-\mathrm{mm}$ anti-aircraft Bofors gun (U.S. version), with the following muzzle velocities: $856 \mathrm{~m} / \mathrm{s}$ for the $12.7-\mathrm{mm}$ bullet, $850 \mathrm{~m} / \mathrm{s}$ for the $40-\mathrm{mm}$ shell. It should be noted that the projectiles are slightly over-calibrated because of the weapon barrel scratches. The overall length of the $12.7-\mathrm{mm}$ bullet is $58.6 \mathrm{~mm}$, the length of its ogival part is about $29 \mathrm{~mm}$. The overall length of the $40-\mathrm{mm}$ shell is 
$180 \mathrm{~mm}$, the length of its ogival part is close to $80 \mathrm{~mm}$ for various types of ammunition (see Fig. 5, and note the flattened tip of the shell).

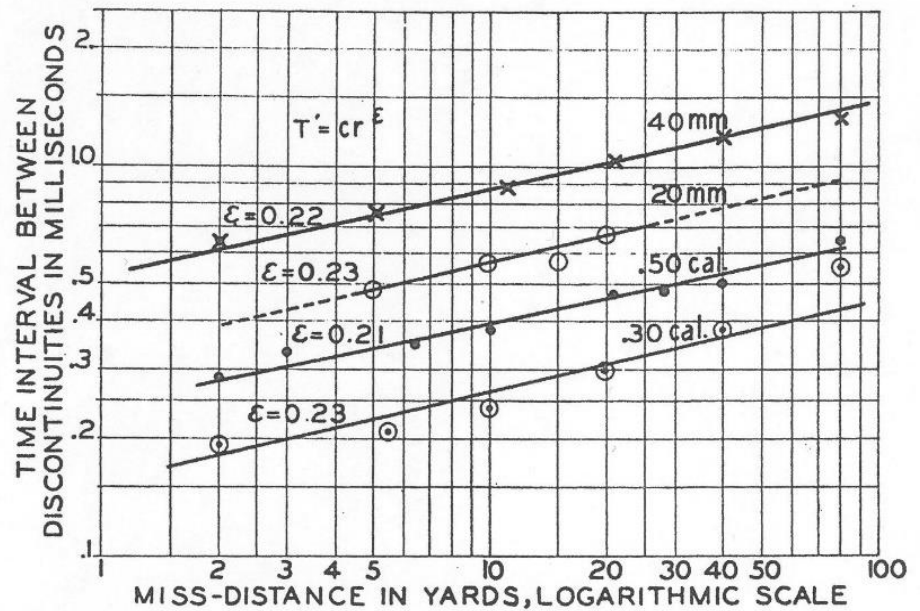

Fig. 6 N-wave period measurements and regression lines (from Ref. [6]).

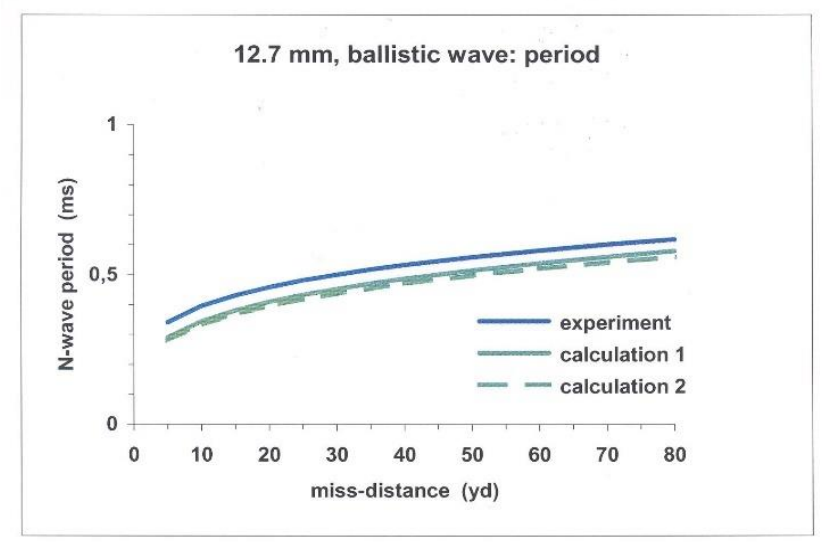

(a)

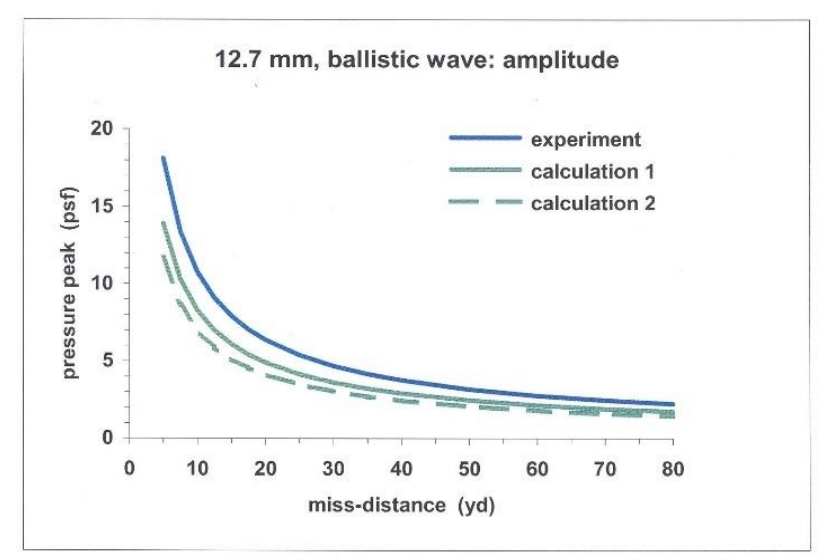

(b)

Fig. 7 Period and amplitude of ballistic wave from 12.7-mm bullets.

To perform the calculations, we have chosen the ambient pressure and temperature which correspond to the CIRA/COSPAR statistical atmosphere [61] for the month of November, latitude $35^{\circ}$ North, at about $748 \mathrm{~m}$ height above sea level (Camp Irwin). The interpolation, made with the help of the 1976 U.S. Standard Atmosphere model, gives the following ambient data: $P_{0}=92,656 \mathrm{~Pa}, \theta_{0}=23.9^{\circ} \mathrm{C}, c_{0}=345.4 \mathrm{~m} / \mathrm{s}$. We have 
supposed that the fly-by speed of the projectiles during the experiments was roughly equal to their muzzle velocity.

As experimental values of pressure peak $\Delta P$ and of overtaking duration $\Delta T$ of the ballistic wave, we can consider the averages determined by Du Mond et al. [6] from several shoots, or better the regression lines derived therefrom: Fig. 6 gives for instance the $\mathrm{N}$-waves periods measured for different calibers and the slopes $\varepsilon$ of the regression lines that are close to the theoretical value 0.25 given by Eq. (8). It should be noted that the measured amplitude $\Delta P$ is less reliable than the period $\Delta T$ for two reasons:

- at short distances (with regard to the projectile caliber), the nonlinear effects lead to an important decreasing in pressure according to the distance;

- Du Mond points out that there are sound reflection effects which are not quantified in his analysis.

These phenomena tend to increase the amplitude compared to the far-field simulation used. In contrast, their influence on the ballistic wave period seems to be negligible.

The estimate of uncertainties linked up to the physical data used in Eq. (4) and (8) leads us to estimate that the global uncertainty of the calculations should not exceed $\pm 20 \%$, mainly due to the shape coefficient taken equal to one (see $\S$ II.B).

From regression lines given in Ref. [6] with logarithmic scales we established the experimental curves shown in Fig. 7 for 12.7-mm caliber and in Fig. 8 for $40-\mathrm{mm}$ caliber. In these figures, the curves "calculation 1" correspond to the shape factors given by Eq. (15) and (16), the curves "calculation 2" correspond to the shape factor given by Eq. (6). We can see that the simulations "calculation 1" (improved model) are slightly better than the simulations "calculation 2" (original model).

The nonlinear effects that increase the N-wave amplitude at short distance appear relatively slight in Fig. 7(b), very important in Fig. 8(b): indeed, 1 yard represents 72 calibers of $12.7 \mathrm{~mm}$ and only 23 calibers of 40 $\mathrm{mm}$. In Fig. 7, since both period and amplitude are underestimated at all distances, it is possible that the chosen shape coefficient is a little too small for the blunt $12.7-\mathrm{mm}$ bullet. In contrast, this shape coefficient appears more adapted for the 40-mm shell, as shown by Fig. 8(a) and 8(b) beyond the range of strong nonlinear effects.

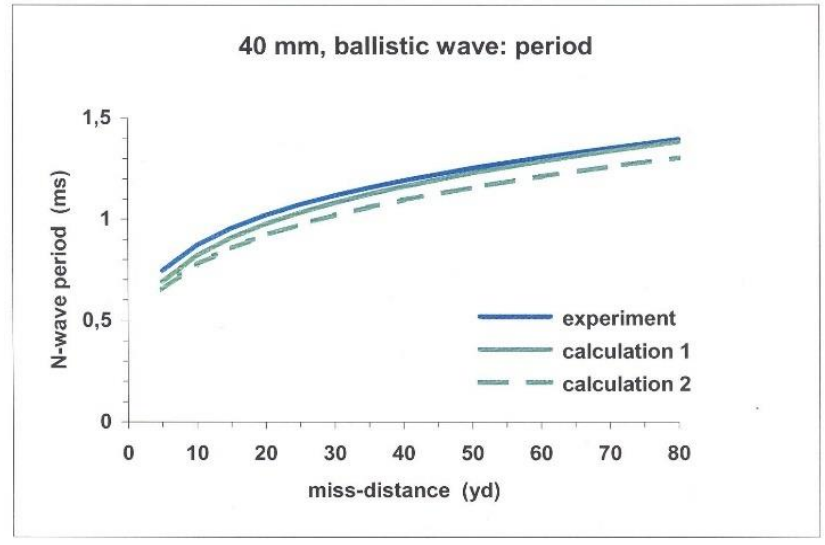

(a)

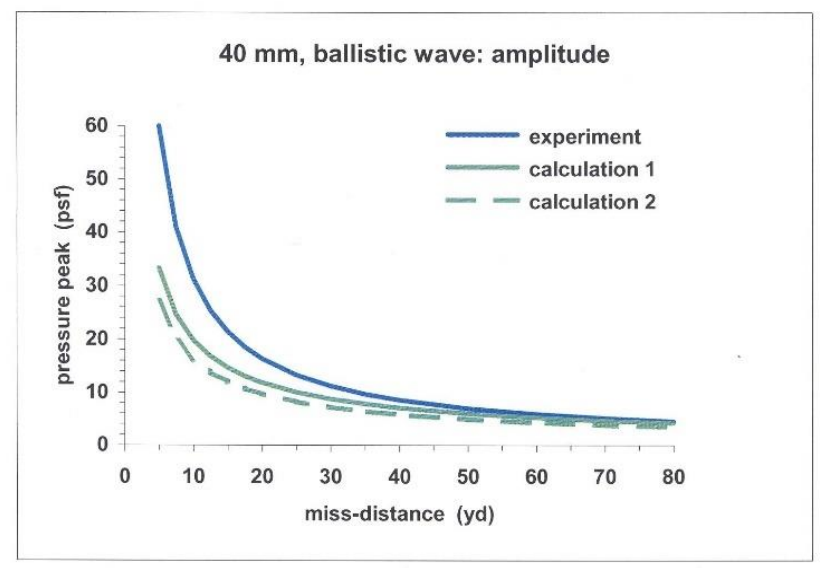

(b)

Fig. 8 Period and amplitude of ballistic wave from $40-\mathrm{mm}$ shells. 
In Fig. 7 and 8, original and improved calculations are in quite good agreement for the period. Provided that the measurements of the period $\Delta \mathrm{T}$ are sufficiently reliable, one can deduce from these measurements, via Eq. (8), the real shape coefficient to be applied to Eq. (16), namely $k_{s} \approx 1.13$ for the 12.7 -mm caliber, $k_{s} \approx 1.04$ for the $40-\mathrm{mm}$ caliber. These values are in accordance with the analysis above and the range of uncertainty for the shape coefficient given in Appendix B.

Concerning the amplitude, it is interesting to notice that Eq. (9) applied to the data $\Delta \mathrm{P}$ and $\Delta \mathrm{T}$ for the 12.7$\mathrm{mm}$ caliber leads to a reflection coefficient varying between 1.3 and 1.4 according to the actual ambient conditions. The modified model does not provide much improvement over the original model, knowing that the latter was originally developed for bullets and small-caliber shells whose shapes and proportions are always more or less the same, but it should be noted that the changes made always act in the right direction.

\section{Sonic boom from Apollo Command Module}

\section{A. Analysis}

The sonic boom from an aircraft flying at supersonic speed is a large-scale ballistic wave which is perceived as a violent detonation for human hearing. The theory applied to the sonic boom is similar to the theory of ballistic wave generated by small projectiles, but includes in addition a "lift function" in order to take into account the effects of wings and incidence [20], and other parameters allowing to adapt the formalism to a nonhomogeneous atmosphere [23-24]. Other specific questions concern the cases of maneuver and acceleration [43], the blunt bodies, the hypersonic speeds, and the very high altitudes [40,44,46]. For a blunt and short body at a hypersonic speed $(M>5)$, Ref. [46] implicitly expresses the sonic boom parameters as a function of a ratio $D / L^{1 / 4}$ similar to that of Eq. (6), which suggested us that the classic formalism could be applied in the following case.

The sonic boom stemming from the Apollo Command Module (A.C.M.) during its reentry into the atmosphere over the Pacific Ocean has been studied in Ref. [41-42] in particular. We are interested in this spacecraft because of its simple and symmetric shape, although it is very compact $-3.43 \mathrm{~m}$ high for $3.91 \mathrm{~m}$ in diameter, see Fig. 9 (a) from Ref. [47] - and has nothing in common with that of a bullet. Another difference is the existence of a lift effect generated by the incidence of the vehicle relative to the flight path (circa $20^{\circ}$ at the beginning of reentry flight).

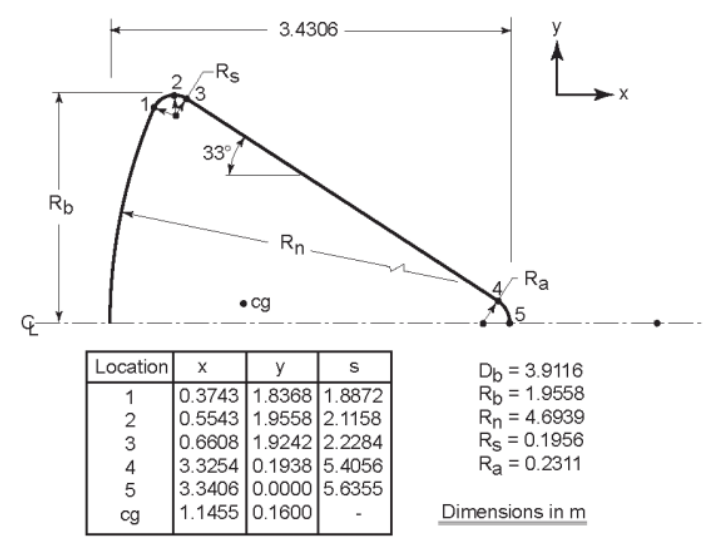

(a)

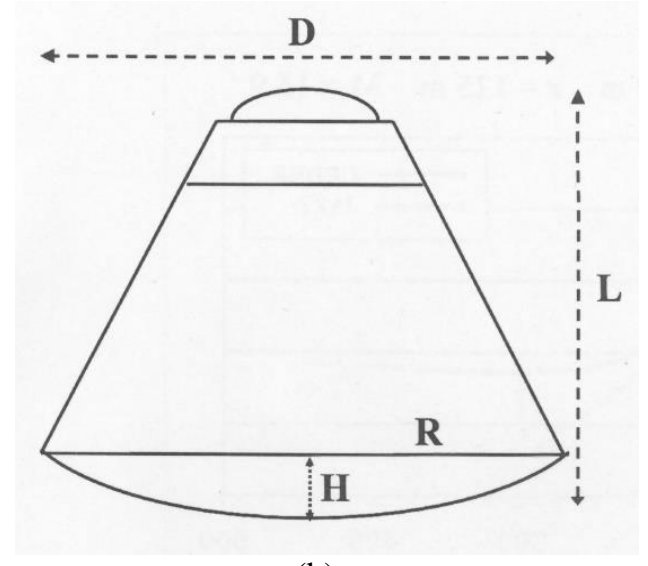

(b)

Fig. 9 Half-outline of Apollo Command Module (from Ref. [47]) and notations used.

The main experimental data of Apollo 15 and Apollo 16 reentries found in Ref. [41-42] are summarized in Table 1, filed according to decreasing altitudes of the flight points. The sonic booms from the spacecraft were recorded aboard several U.S. Navy Ships stationed under the reentry trajectory at selected points where the shock front direction was quasi-perpendicular to the sea surface, as specified in Ref. [41-42]. Overpressure $\Delta P$ and period $\Delta T$ of the sonic boom have been defined as shown by the $\mathrm{N}$-wave profile printed in blue in Fig. 10 (a), without taking into account the intermediate shocks and the shocks occurring after the first come back to ambient pressure (see the real signal printed in red). In Ref. [41] the authors do not explain this choice and attribute the complex form of the signal "to the spacecraft itself", but they suggest possible sound reflections in Ref. [42]. 
Table 1 Flight data and sonic boom parameters (from Ref. [41] and [42])

\begin{tabular}{cccccc}
\hline \hline $\begin{array}{c}\text { US Navy Ship } \\
\text { U.S.S. }\end{array}$ & Flight & $\begin{array}{c}\text { A.C.M. altitude } \\
(\mathrm{m})\end{array}$ & $\begin{array}{c}\text { A.C.M. velocity } \\
(\mathrm{m} / \mathrm{s})\end{array}$ & $\begin{array}{c}\Delta P \\
(\mathrm{~Pa})\end{array}$ & $\begin{array}{c}\Delta T \\
(\mathrm{~ms})\end{array}$ \\
\hline $\begin{array}{c}\text { Genesee } \\
\text { Ponchatoula }\end{array}$ & Apollo 15 & 52,485 & 5134 & 9.4 & 505 \\
Kawishiwi & Apollo 16 & 44,125 & 3156 & 17.4 & 387 \\
Okinawa & Apollo 15 & 33,145 & 1367 & 21.0 & 250 \\
Ticonderoga & Apollo 16 & 25,150 & 617 & 38.3 & 230 \\
& & 24,600 & 528 & 31.3 & 205 \\
\hline \hline
\end{tabular}

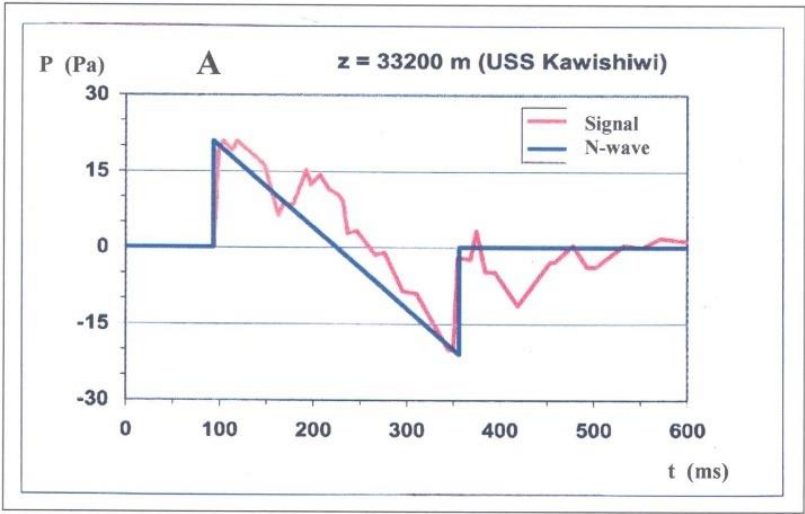

(a)

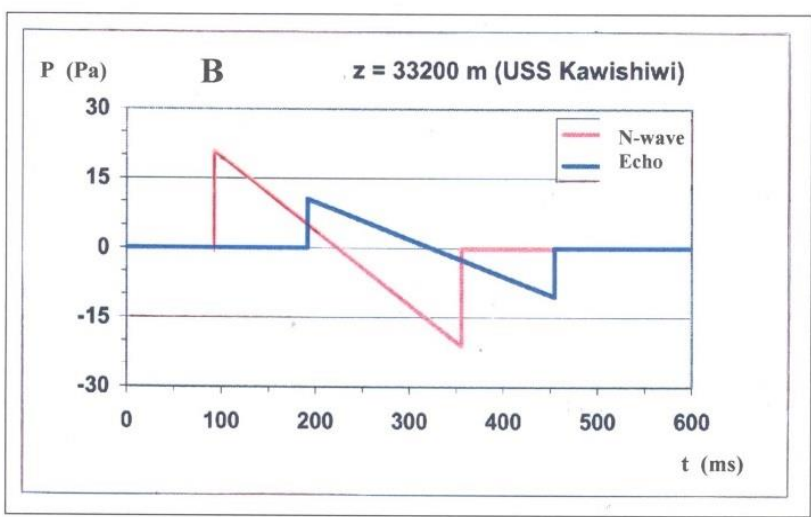

(b)

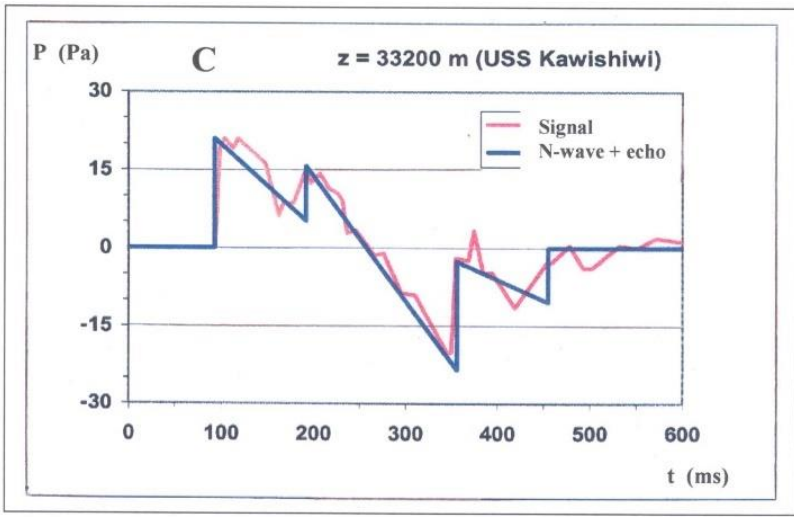

(c)

Fig.10 N-wave such as defined in Ref. [41-42], explanation of the complex form of the signal.

In fact, it is tempting to explain the complex shape of the signal by the superposition of the incident $\mathrm{N}$-wave and of a delayed $\mathrm{N}$-wave of same duration and half-amplitude reflected by the surface of the sea or by a lower 
deck in some cases. Indeed, because the sensors are put on a floor, the amplitude of the incident shock wave is doubled by an acoustic reflection, while the echo coming back from the sea surface reaches the sensors under grazing incidence (diffracted sound field) and is therefore not amplified.

Knowing that the wave front hits the surface of the sea more or less perpendicularly, one can verify that the delay of the second peak corresponds to the time of a return-trip between the deck level and the sea, at least in the case of the carrier USS Ticonderoga and of the amphibious assault ship USS Okinawa where the sensors were put on the aft part of the flight-deck [41-42]. In all cases, the profile of the real signal is well reproduced by the superposition mechanism shown in Fig. 10 (b) and (c), which finally justifies the values of the N-wave parameters specified in Table 1. In Fig. 11, the differences in amplitude between signal and N-wave superposition model probably reveal a dissymmetrical incident $\mathrm{N}$-wave including a relatively small underpressure.

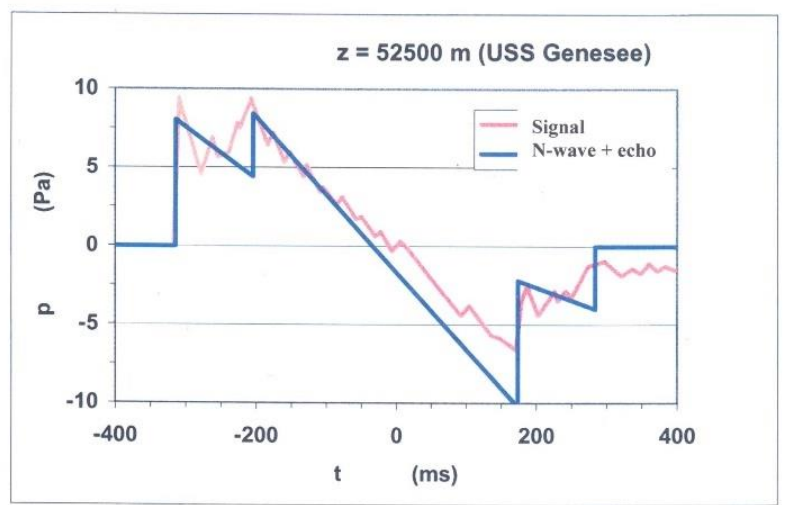

Fig. 11 Signal recorded aboard USS Genesee and N-wave superposition model.

References [41-42] also give weather data concerning the day of the A.C.M. splashdown. Unfortunately, these weather data are too incomplete for allowing a precise calculation of sound propagation. Table 2 gives some provided data, the other ones coming from the CIRA/COSPAR statistical meteorology [61] for the month of August, latitude $25^{\circ}$ North on the one hand (Apollo 15 mission), for the month of April, latitude $0^{\circ}$ to $5^{\circ}$ South on the other hand (Apollo 16 mission). For every flight point, pressure and temperature are given at the altitude of the spacecraft (index $z$ ) and at sea level (index 0 ). It is interesting to notice that these data are sufficient for calculating approximately the sonic boom parameters at sea level (see Appendix C, § C2).

Table 2 Atmospheric parameters taken into account in altitude and at sea level

\begin{tabular}{cccccc}
\hline \hline Flight & $\begin{array}{c}\text { A.C.M. altitude } z \\
(\mathrm{~m})\end{array}$ & $\begin{array}{c}\text { Pressure } P_{Z} \\
(\mathrm{~Pa})\end{array}$ & $\begin{array}{c}\text { Temperature } T_{Z} \\
(\mathrm{~K})\end{array}$ & $\begin{array}{c}\text { Pressure } P_{0} \\
(\mathrm{~Pa})\end{array}$ & $\begin{array}{c}\text { Temperature } T_{0} \\
(\mathrm{~K})\end{array}$ \\
\hline Apollo 15 & 52,485 & 61 & 258.7 & 101,300 & 300.0 \\
Apollo 16 & 44,125 & 177 & 269.3 & 100,770 & 301.5 \\
Apollo 15 & 33,145 & 768 & 227.0 & 101,300 & 301.0 \\
Apollo 15 & 25,150 & 2530 & 220.8 & 101,300 & 300.0 \\
Apollo 16 & 24,600 & 2640 & 215.9 & 100,770 & 301.5 \\
\hline \hline
\end{tabular}

\section{B. CFD calculations}

It should be noted that speed and altitude of the space vehicle at some flight points are considerably beyond the technical limits of the military aircraft - at the most Mach 3 at 26,000 m high for the plane SR-71 Blackbird, see also Ref. [31,33] - and therefore out of the usual application domain of the semi-empirical models of sonic boom applying Whitham's formalism.

For this reason, ONERA has performed a preliminary study concerning the aerodynamic and thermochemical conditions of reentry at high altitude, and at hypersonic speed, using the CFD codes CELHyO-2D and CEDRE.

In order to determine the most suitable physics for rarefied atmosphere, and in the presence of very high temperatures ahead of the heatshield, at the stagnation point in particular, preliminary Navier-Stokes computations of aerodynamic wake allowed us to test:

- the cases of chemical equilibrium and non-equilibrium for a five-species air mixture (Fig. 12);

- the cases of laminar flow and of turbulent flow. 


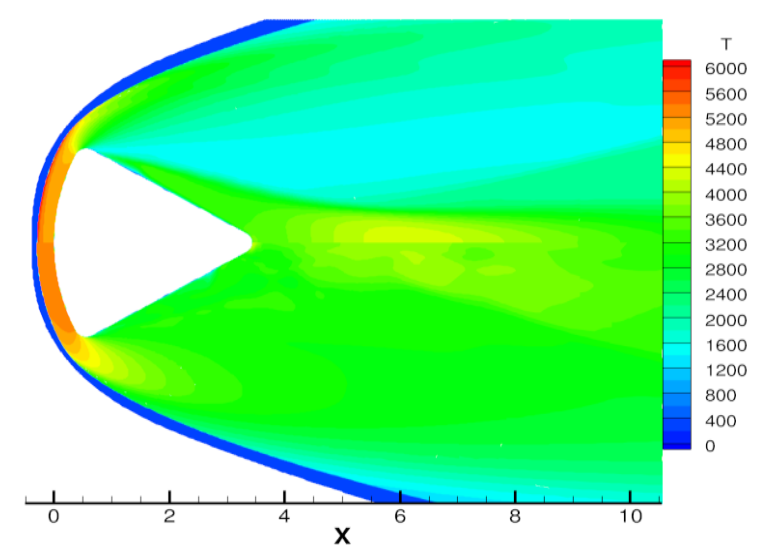

Fig. 12 Navier-Stokes computations with chemical equilibrium (bottom) and non-equilibrium (top).

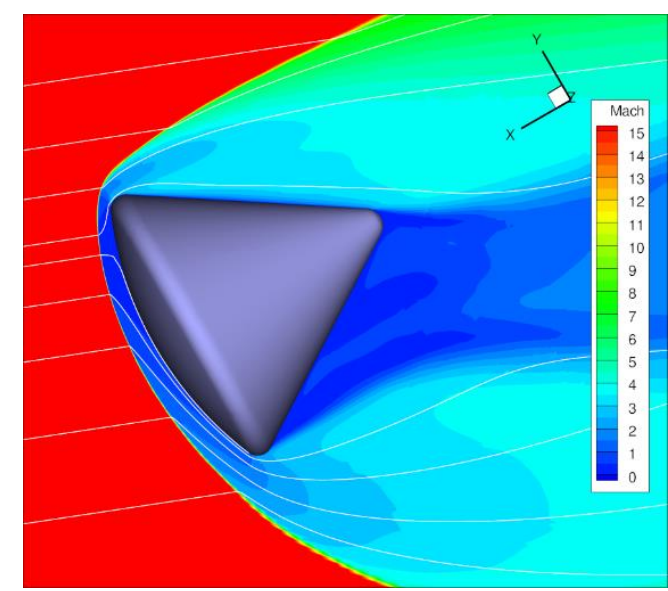

Fig. 13 Navier-Stokes computations with turbulent flow and chemical non-equilibrium $(z=\mathbf{5 2 , 5 0 0} \mathbf{m})$

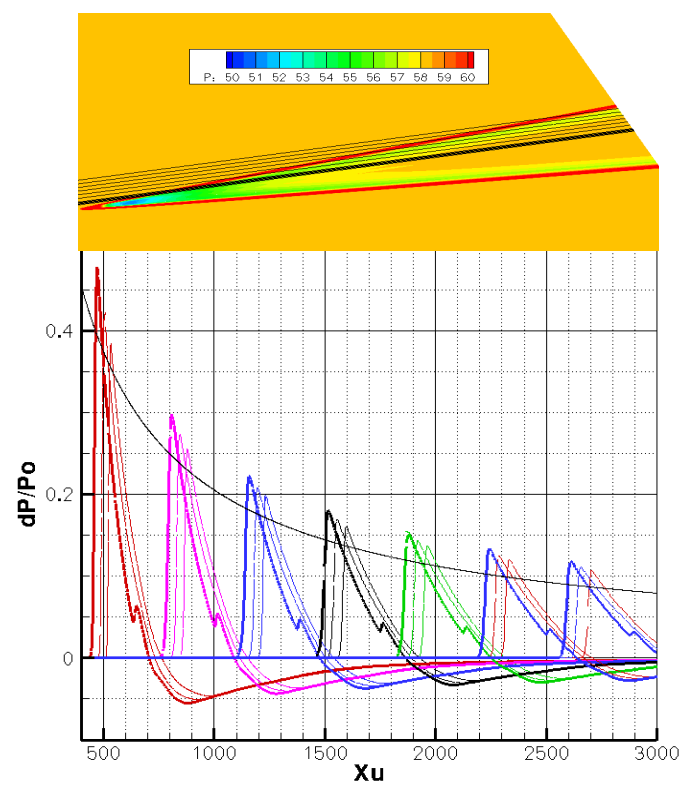

Fig. 14 Pressure profiles at various distances from the flight path (Apollo 15, $z=52,500 \mathrm{~m}$ ).

The final computations concern the flight points at altitudes $z=44,000 \mathrm{~m}$ and $z=52,500 \mathrm{~m}$ and take into account both the slope of the flight path and the incidence of the vehicle (Fig. 13). The Navier-Stokes 3D 
computation is done under the most realistic conditions allowed by the CEDRE code. The main conclusions of the study are the following:

- the diameter of the vehicle is large enough so that the laws of fluid dynamics remain applicable at the considered altitudes, under the continuum limit;

- because of the rounded shape of the heatshield, the shock is detached from the wall and the incidence relative to the path (circa $20^{\circ}$ ) has a negligible influence on the pressure profiles in the "shadow zone" (Fig. 13, at the top) and in the "illuminated zone" (Fig 13, at the bottom);

- the nearby pressure profiles of the aerodynamic wake are not classic $\mathrm{N}$-waves, but they are similar to a blast wave profile with an asymptotic return to the ambient pressure: in Fig. 14 (at the bottom), the pressure profiles are computed along the black lines which go through the wake at various distances from the axis (at the top).

Using the nonlinear propagation code TRAPS [25], we checked the processing of the pressure profiles of Fig. 14 into $\mathrm{N}$-waves, a conversion that occurs gradually (see Fig. 15). Unfortunately, the N-wave period found at sea level is too long (about $+50 \%$ compared with the measurement), perhaps because of the rarefied atmosphere and of the unusual pressure profile at the origin: it is curious to remark in Fig. 14 that the signature of a very short body at a hypersonic speed looks like that of a body of infinite length [40,43].

Finally, knowing from the computation that the pressure differences between "shadow zone" and "illuminated zone" of the aerodynamic wake stay within $\pm 15 \%$ in near-field, it seems possible and acceptable to use the semi-empirical models of sonic boom for the highest flight points, assuming zero incidence and symmetrical aerodynamic field. In the following, we will extend this approximation to the entire set of flight points, assuming that the lift effects can be ignored at least in the first analysis.

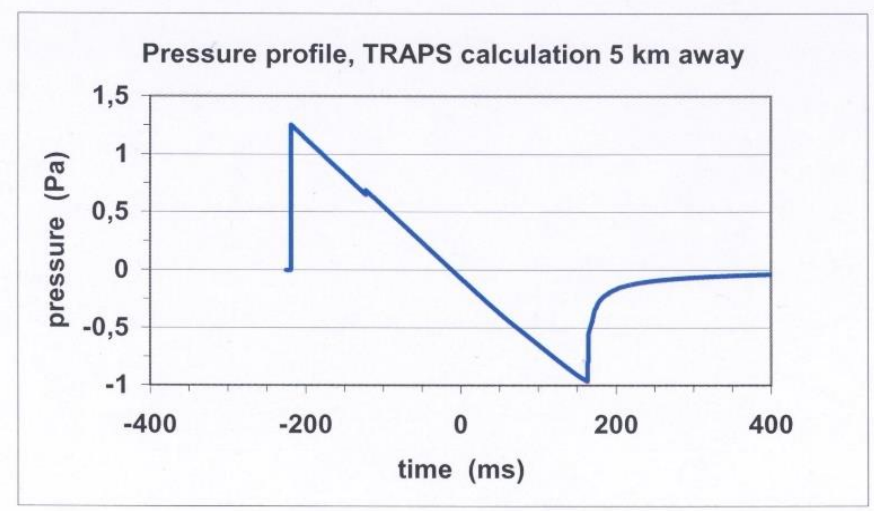

Fig. 15 Pressure profile at $5 \mathrm{~km}$ from the flight path (Apollo 15, $z=52,500 \mathrm{~m}$ ).

\section{Semi-empirical calculations}

In Ref. [41] are given the results of a preflight simulation of sonic boom with a semi-empirical model based in part on Whitham's theory, namely the "first-cut method" of Ref. [23]. We can see in Table 3 that the calculated overpressures agree very well with the measured overpressures of Table 1, with an average error less than $10 \%$ and a relative uncertainty of the same order (standard deviation $\sigma_{\mathrm{n}-1}$ for some data). In contrast, the wave periods are clearly overestimated with an average error close to $50 \%$. We can suppose that this fact is linked up with the very compact shape of the spacecraft that cannot be taken into account by the theoretical model used. Note that the Mach number 1.7 indicated in Table 3 for $\mathrm{z}=25,150 \mathrm{~m}$ is too small compared with the speed $617 \mathrm{~m} / \mathrm{s}$ indicated in Table 1 and has been set to 2 in the following calculations.

For calculating the sonic boom parameters with our semi-empirical code JAZZ that applies both the "original model" and the "improved model" defined in Section II D, we supposed that:

- the lift effects can be neglected in a first step,

- the amplitude of the incident $\mathrm{N}$-wave is doubled by the sound reflection (sensors put on the deck),

- the propagation distance is taken equal to the altitude of the spacecraft,

- the sonic boom parameters at sea level can be deduced from the sonic boom parameters in altitude via the "transformation formulas" indicated in Appendix C2 and the weather data of Table 2.

For the improved model, the JAZZ code uses the resulting Equations (18) and (19) given by convenience in $\S$ IV.A, by taking $h \approx z$ and $k_{L} \approx 1$, neutral value of the lift coefficient. For the original model, a single shape factor $F_{W}$ in used in both equations. In addition, the code calculates the atmospheric parameters required at a given altitude from data of a real, standard or statistical atmosphere.

The A.C.M. geometric parameters from Fig. 9 (a-b) taken into account are the following:

- overall length $L=3.431 \mathrm{~m}$,

- maximum radius $R=1.956 \mathrm{~m}$, 
- maximum diameter $D=3.912 \mathrm{~m}$,

- height of the heatshield $H=0.554 \mathrm{~m}$,

by assuming that the dimensions of Apollo 15 and 16 Command Modules are the same as those of Apollo 6 [47].

The results obtained with the original model are given in Table 4 . We can see that the calculation of the $\mathrm{N}$ wave periods is quite good, with an average error of $10 \%$ and a relative uncertainty of $14 \%$. Unfortunately, the $\mathrm{N}$-wave amplitudes are underestimated, with an average error of $-33 \%$ and an uncertainty of about $20 \%$.

It should be noted that the ratios $\triangle P / \Delta T$ for the sonic booms calculated for USS Kawishiwi and for USS Okinawa are practically the same in Table 3 and in Table 4: that shows, via Eq. (9), that the models used both have a single shape factor for amplitude $\Delta P$ and period $\Delta T$ (see also $\S$ IV.B). For the original model, Eq. (6) gives here $F_{W} \approx 1.437$. In summary, it appears that amplitude and period cannot be simulated in an accurate manner simultaneously.

The results obtained with the improved model taking into account the heatshield height and two distinct shape factors for amplitude and period are given in Table 5. The sonic boom parameters are underestimated for the highest altitudes and overestimated for the lowest altitudes but stay in an acceptable margin of error, namely an uncertainty close to $30 \%$ for amplitude, $12 \%$ for period, with average errors of $5 \%$ and $0 \%$ respectively. These latter values suggest that the lift coefficient $k_{L}$ taken equal to one by default can hardly be modified. In fact, the good result rather consists in the coherence between calculated amplitude and calculated period at every altitude.

Note that the shape factors given by Eq. (15) for amplitude and by Eq. (16) for period are $F_{W} \Delta P \approx 2.267$ and $F_{W \Delta T} \approx 1.305$ respectively.

Table 3 Flight data and calculated sonic boom parameters (from Ref. [41])

\begin{tabular}{|c|c|c|c|c|c|c|c|}
\hline $\begin{array}{c}\text { US Navy Ship } \\
\text { U.S.S. }\end{array}$ & Flight & $\begin{array}{l}\text { Altitude } \\
\text { (m) }\end{array}$ & $\begin{array}{l}\text { Mach } \\
\text { number }\end{array}$ & $\begin{array}{l}\Delta P \\
(\mathrm{~Pa})\end{array}$ & $\begin{array}{l}\text { Relative } \\
\text { Error }\end{array}$ & $\begin{array}{l}\Delta T \\
(\mathrm{~ms})\end{array}$ & $\begin{array}{c}\text { Relative } \\
\text { error }\end{array}$ \\
\hline Genesee & Apollo 15 & 52,485 & 16. & 11.0 & $+16.8 \%$ & 644 & $+27.5 \%$ \\
\hline Kawishiwi & Apollo 15 & 33,145 & 4.5 & 23.0 & $+9.6 \%$ & 449 & $+79.6 \%$ \\
\hline Okinawa & Apollo 15 & 25,150 & 1.7 & 36.9 & $-3.7 \%$ & 317 & $+37.8 \%$ \\
\hline \multicolumn{5}{|c|}{ Average error } & $+7.6 \%$ & & $+48.3 \%$ \\
\hline \multicolumn{5}{|c|}{ Relative uncertainty } & $10.4 \%$ & & $27.6 \%$ \\
\hline
\end{tabular}

Table 4 Flight data and calculated sonic boom parameters (original model)

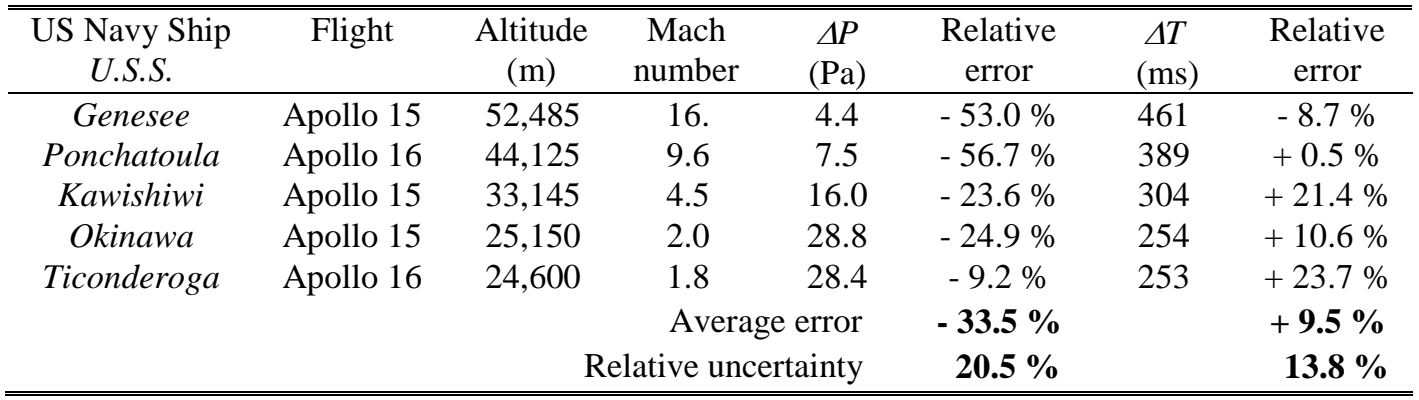

Table 5 Flight data and calculated sonic boom parameters (improved model)

\begin{tabular}{cccccccc}
\hline $\begin{array}{c}\text { US Navy Ship } \\
\text { U.S.S. }\end{array}$ & Flight & $\begin{array}{c}\text { Altitude } \\
(\mathrm{m})\end{array}$ & $\begin{array}{c}\text { Mach } \\
\text { number }\end{array}$ & $\begin{array}{c}\Delta P \\
(\mathrm{~Pa})\end{array}$ & $\begin{array}{c}\text { Relative } \\
\text { Error }\end{array}$ & $\begin{array}{c}\Delta T \\
(\mathrm{~ms})\end{array}$ & $\begin{array}{c}\text { Relative } \\
\text { error }\end{array}$ \\
\hline Genesee & Apollo 15 & 52,485 & 16. & 7.0 & $-25.8 \%$ & 418 & $-17.1 \%$ \\
Ponchatoula & Apollo 16 & 44,125 & 9.6 & 11.9 & $-31.7 \%$ & 353 & $-8.8 \%$ \\
Kawishiwi & Apollo 15 & 33,145 & 4.5 & 25.4 & $+21.1 \%$ & 277 & $+10.7 \%$ \\
Okinawa & Apollo 15 & 25,150 & 2.0 & 45.4 & $+18.5 \%$ & 231 & $+0.4 \%$ \\
Ticonderoga & Apollo 16 & 24,600 & 1.8 & 44.8 & $+43.2 \%$ & 230 & $+12.3 \%$ \\
& & Average error & $\mathbf{+ 5 . 1 \%}$ & $\mathbf{0 . 5} \%$ \\
& \multicolumn{3}{c}{ Relative uncertainty } & $\mathbf{3 2 . 4 \%}$ & $\mathbf{1 2 . 6 \%}$ \\
\hline \hline
\end{tabular}

Of course, the problem of A.C.M. atmospheric reentry contains many unknowns and uncertainties: for this reason, it could be solved only approximately, and the results obtained must be considered from a purely qualitative point of view. 


\section{Sonic boom from slender bodies}

\section{A. Rocket shape}

The theory of ballistic wave and sonic boom, especially that of Whitham, applies preferably to slender and pointed bodies moving at slightly supersonic speed. The case of the Apollo Command Module is obviously far from these ideal conditions. It is therefore necessary to test the models from experiments closer to the domain of application of the theory. Unfortunately, it is difficult to find practical examples in the literature, apart from applications to projectiles of light weapons which hardly allow to discriminate between the models, as discussed in Section II.D.

Apart from that of bullets and shells the rocket has the simplest shape, but in reality its aerodynamic features are made complex by the presence of jets from rocket-engines, as those of the launch vehicle Saturn V [24,43]. To test the semi-empirical models, we must therefore content ourselves with a standard shape of rocket and the results of calculations deemed accurate for simulating the sonic boom, namely CFD and nonlinear propagation. Such calculations are shown in Appendix C1 with a rocket shape of nominal proportions $H=L / 5, R=H / 5$, therefore much more elongated than that of common projectiles $(H \approx L / 2, R \approx H / 4)$. The reference length is $L=8$ $\mathrm{m}$.

The sonic boom received on the ground was calculated under realistic flight conditions derived from the performances of the U.S. MIM-23 Hawk surface-to-air missile, in service in the French Army for a long time. In the example given in Appendix C1, a Mach number $M=1.7$ for an altitude $z=8000 \mathrm{~m}$ was adopted. To calculate the sonic boom parameters, the U.S. standard atmosphere model and the "transformation formulas" (c1) and (c2) of Appendix C2 are used. After substitution of these formulas and for a horizontal flight, the equations used to calculate amplitude and duration of sonic boom at altitude $z$ become, under the flight path and at ground level:

$$
\begin{aligned}
& \Delta P_{o}=2 \sqrt{P_{o} P_{Z}} 2^{1 / 4} \gamma(\gamma+1)^{-1 / 2}\left(M^{2}-1\right)^{1 / 8} k_{L} F_{W \Delta P} h^{-3 / 4} \\
& \Delta T_{o}=\frac{1}{c_{o}} 2^{5 / 4}(\gamma+1)^{1 / 2} M\left(M^{2}-1\right)^{-3 / 8} k_{L} F_{W \Delta T} h^{1 / 4}
\end{aligned}
$$

$h=z-z_{0}$ being the altitude of the flying object with respect to the ground and $k_{L}$ a lift coefficient assumed equal to 1 in the case of a body of revolution. As in the case of Apollo Command Module, a reflection factor equal to 2 is taken into account for $\Delta P$.

Table 6 Sonic boom simulations for a flying rocket

\begin{tabular}{ccccc}
\hline \hline $\begin{array}{c}\text { Numerical } \\
\text { simulation }\end{array}$ & $\begin{array}{c}\Delta P \\
(\mathrm{~Pa})\end{array}$ & $\begin{array}{c}\text { Relative } \\
\text { error }\end{array}$ & $\begin{array}{c}\Delta T \\
(\mathrm{~ms})\end{array}$ & $\begin{array}{c}\text { Relative } \\
\text { Error }\end{array}$ \\
\hline$C F D+$ TRAPS & 44.6 & $0 \%$ & 45.3 & $0 \%$ \\
Improved model & 48.5 & $+8.7 \%$ & 44.5 & $-1.8 \%$ \\
Original model & 32.5 & $-27.1 \%$ & 26.9 & $-40.6 \%$ \\
& & & & \\
\hline \hline
\end{tabular}

Equation (18) includes a simplification by $P_{z}{ }^{1 / 2}, P_{z}$ being the ambient pressure at altitude $z$. After simplifying by $c_{z}$, Eq. (19) appears to be identical to Eq. (8), but the sound speed at altitude $z$ still intervenes in the Mach number $M$. The shape factors for amplitude and period are given by Eq. (15) and (16). In the "original model", a single shape factor $F_{W}$ given by Eq. (6) is used. It should be noted that the lift coefficient $k_{L}$ should be considered as part of the shape factor in Eq. (18) and (19).

Table 6 gives the results of the various simulations of the sonic boom received on the ground with the flight conditions $M=1.7, z=8,000 \mathrm{~m}$. The reference simulation CFD + TRAPS is the one used in Appendix C1 under the nominal conditions (for the amplitude, an average value of $\Delta P^{+}$and $\Delta P^{-}$is taken into account). The "improved model" which uses the shape factors of Eq. (15) and (16) gives results close to the reference simulation, whereas the original model using a single shape factor is clearly in default. This was foreseeable, since Eq. (6) as well as Whitham's theory stem from the study of the ballistic wave of small projectiles of relatively compact shape. With this elongated body, we have here $R / H^{1 / 4} \approx 0.285$ and $R / L^{1 / 4} \approx 0.190$, values whose ratio of 1.50 is also that of the amplitudes $\Delta P$ provided by the two models.

\section{B. Aircraft sonic boom}

Another way to test the models is to refer to the numerous experimental data concerning sonic booms from military aircraft [30,33-35] or from the French-British airliner Concorde. The difficulty is that the theory valid 
for bodies of revolution is poorly adapted for aircraft, in particular because of the lift effects. However, ONERA carried out a few simulations of sonic boom with an interim model, referring to the tests carried out during the 1950s-1970s by the Air Force Flight Test Center of Bretigny, France, and the French-German Institute of SaintLouis, France, among others. The airplanes used were the fighter Dassault Mirage III, the strategic bomber Dassault Mirage IV and the supersonic airliner Concorde. Because sonic boom calculations gave too small results for the amplitude in particular, we have assumed that the lift coefficient $k_{L}$ could be different for the period and for the amplitude. We finally determined the empirical relationship below:

$$
1 \leq k_{L \Delta T} \leq k_{L \Delta P} \leq 1.5
$$

by adopting sometimes, for lack of anything better, the practical values $k_{L \Delta T} \approx 1$ and $k_{L \Delta P} \approx 1.5$.

The formalism used in the literature to deal with the problem is in fact more complex. In the "first-cut method" of Carlson [23-24], the lift parameter $K_{L}$ is expressed according to physics considerations:

$$
K_{L}=\frac{W \sqrt{M^{2}-1}}{1.4 P_{z} M^{2} L^{2}}
$$

equation in which $W$ is the weight of the aircraft, the term $L^{2}$ representing a wing area. The amplitude of sonic boom at ground level is given by:

$$
\Delta P=2 \sqrt{P_{0} P_{z}} K_{P}\left(M^{2}-1\right)^{1 / 8} L^{3 / 4} K_{S} h^{-3 / 4}
$$

where $K_{P}$ is an "atmospheric amplification factor" depending on the altitude and the Mach number via experimental curves. $K_{S}$ is the shape factor that is a function of the lift parameter $K_{L}$ but also of the aircraft type (Fig.16), which is far from any mathematical consideration.

Equation (22) is to be compared with Eq. (18), the homologous elements being written in the same order. One finds for example the expression $\left(P_{0} P_{Z}\right)^{1 / 2}$ which results from the formula (c1) of the simplified propagation model described in Appendix C2. On the other hand, the unexpected term $L^{3 / 4}$ has no equivalent in Eq. (18) and must be considered as part of the shape factor $K_{S}$. Indeed, in an earlier paper [30], an expression of the amplitude $\Delta P_{0}$ was found, in which the classic term $D / L^{1 / 4}$, where $D$ is the "equivalent-body diameter", is artificially replaced by the product $(D / L) L^{3 / 4}$, which allows to obtain the terms $(D / L)$ and $(L / h)^{3 / 4}$ and to express the lengths in feet rather than in meters - which is also the case for Eq. (22).

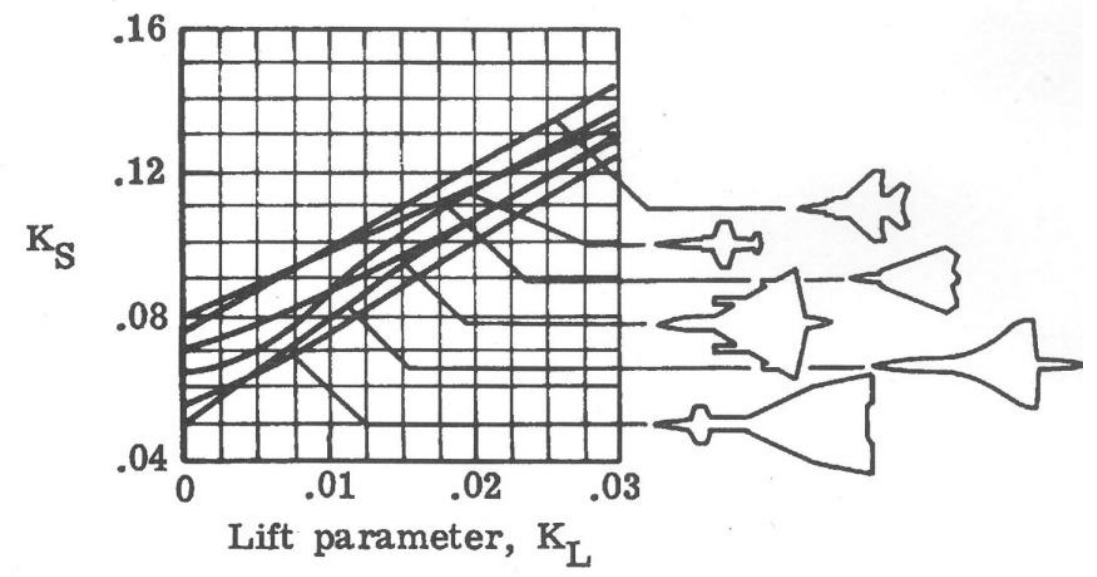

Fig. 16 Aircraft shape factor $K_{S}$ (from Ref. [24]).

The duration of the sonic boom is given by the equation:

$$
\Delta T=\frac{K_{T}}{c_{z}} 3.42 M\left(M^{2}-1\right)^{-3 / 8} L^{3 / 4} K_{S} h^{1 / 4}
$$

which is arranged in the same order as Eq. (19). We note that the term $1 / c_{0}$ of Eq. (19) is replaced by the ratio $K_{T} / c_{z}$ where $K_{T}$ is the "signature time factor", given by experimental curves according to altitude and Mach number. This factor is equal to 1 at the altitude $z=0$ and then decreases when the altitude increases. 
In fact, it will be seen in the numerical application of $\S$ IV.C that:

$$
\frac{K_{T}}{c_{z}} \approx \frac{1}{c_{0}}
$$

Indeed, for altitudes ranging between 4 and $11 \mathrm{~km}$ and Mach numbers varying from 1.15 to 1.70 , Eq. (24) gives as average for the sound speed at sea level $\mathrm{c}_{0} \approx 334.6 \pm 4.4 \mathrm{~m} / \mathrm{s}$, which suggests that the formula (c2) of Appendix C2 constitutes an acceptable approximation.

In addition, we can see that Eq. (23) uses the same shape factor $L^{3 / 4} K_{S}$ as Eq. (22).

\section{Application case}

In order to make meaningful comparisons between models and with other applications, we thought it was necessary to choose an airplane whose shape is as simple as possible and relatively close to a body of revolution. The Lockheed F-104 Starfighter, with its short wings located towards the rear of the fuselage, seems to correspond to this definition (Fig. 18). Complete flight data and measurements are provided in Ref. [35], as well as the surface temperature and the weather conditions of the day. Moreover, the ranges of flight altitudes and velocities tested, correspond well to the field of application of the theory.

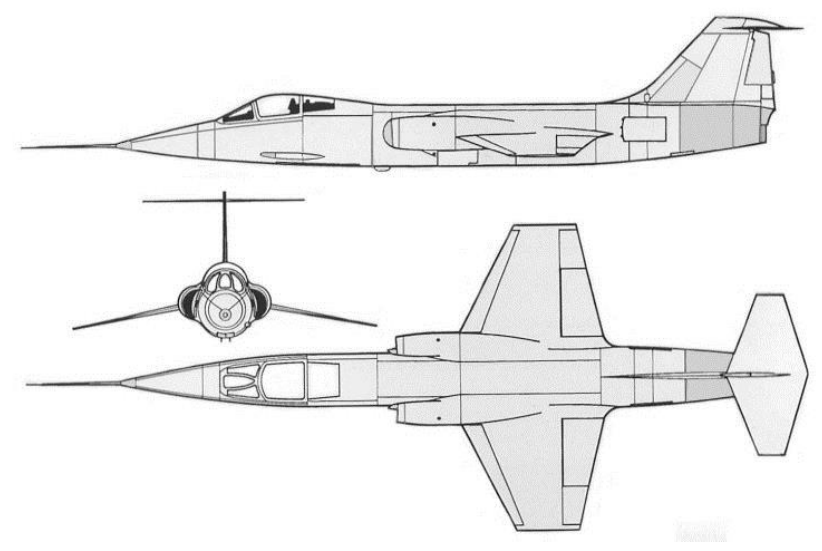

Fig. 17 Drawing of the fighter Lockheed F-104

The characteristics of the F-104 fighter used in the simulations are a weight of $6350 \mathrm{~kg}(W \approx 62,300 \mathrm{~N})$ and an overall length $L$ of $16.60 \mathrm{~m}$. From the drawing of the front part of the fuselage (Fig. 17), we estimated the radius $R$ at $0.65 \mathrm{~m}$ and the length $H$ of the ogival part at $5.75 \mathrm{~m}$. This results in the $R / H^{1 / 4} \approx 0.420$ and $R / L^{1 / 4} \approx$ 0.322 , values which give a ratio of 1.30 for the amplitudes stemming from the two theoretical models, and a ratio 1.46 for the periods because of the factor $K_{\Delta T}=1.124$ of Eq. (14). These ratios allow to deduce the results of one of the two models from those of the other model. Concerning the Carlson's model [24], the profile of the F-104 is the symbol of the "small fighter" curve running through the point $\left[K_{L}=0.005, K_{S}=0.07\right]$ in Fig. 16.

Flight tests were conducted by U.S. Air Force and NASA Flight Research Center in the vicinity of Edwards Air Force Base (California) during the period from June 1966 to January 1967 [35]. The test site (microphone arrays) was at an elevation $z_{0} \approx 700 \mathrm{~m}$ above sea level. Airplane F-104 was used for 124 flights, but we retained only fly-by altitudes less than $11,000 \mathrm{~m}$ and the sonic booms recorded under the flight path or with an offset less than $400 \mathrm{~m}$. The values of the parameters $\Delta P$ and $\Delta T$ retained for each flight are averages made on at least 5 microphones. A microphone fastened on a mast enables us to verify that the reflection factor for the amplitude of the other microphones put down on the ground is well equal to 2 .

Table 7 Flight data and sonic boom parameters (from data of Ref. [35])

\begin{tabular}{ccccccccc}
\hline \hline $\begin{array}{c}\text { Mach } \\
\text { number }\end{array}$ & $\begin{array}{c}\text { Altitude z } \\
(\mathrm{m})\end{array}$ & $\begin{array}{c}\text { Nb. of } \\
\text { flights }\end{array}$ & $\begin{array}{c}\Delta P \\
(\mathrm{~Pa})\end{array}$ & $\begin{array}{c}\sigma_{n} \\
(\mathrm{~Pa})\end{array}$ & $\begin{array}{c}\sigma_{n} \\
(\%)\end{array}$ & $\begin{array}{c}\Delta T \\
(\mathrm{~ms})\end{array}$ & $\begin{array}{c}\sigma_{n} \\
(\mathrm{~ms})\end{array}$ & $\begin{array}{c}\sigma_{n} \\
(\%)\end{array}$ \\
\hline $1.15-1.30$ & $4,280-5,220$ & 8 & 147.4 & 31.7 & \pm 21.5 & 81.5 & 8.7 & \pm 10.6 \\
$1.30-1.40$ & $6,150-6,680$ & 11 & 99.0 & 15.5 & \pm 15.6 & 77.0 & 3.5 & \pm 4.6 \\
$1.40-1.55$ & $8,570-9,120$ & 8 & 72.7 & 8.8 & \pm 12.2 & 82.9 & 5.4 & \pm 6.5 \\
$1.55-1.70$ & $8,870-10,860$ & 10 & 63.5 & 9.7 & \pm 15.2 & 78.2 & 4.8 & \pm 6.1 \\
\hline \hline
\end{tabular}


Table 8 Flight data and sonic boom parameters (improved model)

\begin{tabular}{ccccccccc}
\hline \hline $\begin{array}{c}\text { Mach } \\
\text { number }\end{array}$ & $\begin{array}{c}\text { Altitude z } \\
(\mathrm{m})\end{array}$ & $\begin{array}{c}\text { Nb. of } \\
\text { flights }\end{array}$ & $\begin{array}{c}\Delta P \\
(\mathrm{~Pa})\end{array}$ & $\begin{array}{c}\sigma_{n} \\
(\mathrm{~Pa})\end{array}$ & $\begin{array}{c}\sigma_{n} \\
(\%)\end{array}$ & $\begin{array}{c}\Delta T \\
(\mathrm{~ms})\end{array}$ & $\begin{array}{c}\sigma_{n} \\
(\mathrm{~ms})\end{array}$ & $\begin{array}{c}\sigma_{n} \\
(\%)\end{array}$ \\
\hline $1.15-1.30$ & $4,280-5,220$ & 8 & 118.7 & 10.9 & \pm 9.2 & 65.2 & 4.1 & \pm 6.3 \\
$1.30-1.40$ & $6,150-6,680$ & 11 & 87.6 & 2.9 & \pm 3.3 & 63.8 & 1.6 & \pm 2.5 \\
$1.40-1.55$ & $8,570-9,120$ & 8 & 57.0 & 1.8 & \pm 3.2 & 66.9 & 1.3 & \pm 1.9 \\
$1.55-1.70$ & $8,870-10,860$ & 10 & 56.8 & 4.3 & \pm 7.6 & 66.6 & 1.1 & \pm 1.7 \\
\hline \hline
\end{tabular}

Thirty-seven flights are taken into account in the four speed and altitude ranges of Table 7. The values of the sonic boom parameters $\Delta P$ and $\Delta T$ indicated in the table are their average values in each band. The standard deviations $\sigma_{n}$ for amplitude and period are also translated into relative uncertainty. It can be seen that this uncertainty is twice as great for the amplitude as for the period, the extreme values of these parameters corresponding sometimes to a clear sky, sometimes to an overcast sky. One can note the regular variation of the amplitude according to the flight data while the period remains more or less constant.

The U.S. standard atmosphere is used for the sonic boom simulations, the temperature measured at the ground [35] giving the requested temperature offset. The "improved model" is applied to every flight without lift correction $\left(k_{L}=1\right)$. Next, Table 8 is established on the same model as Table 7 . The uncertainties concerning the calculated amplitude and period are logically lower than those of the actual parameters, the maximum values being found in the range of the smallest Mach numbers. The evolution of sonic boom parameters $\Delta P$ and $\Delta T$ as a function of Mach number and altitude is the same in both tables, which confirms the significant nature of the measurements and of the mode of exploitation we have adopted.

The value of the lift coefficient $k_{L}$ to be applied to the model can now be defined empirically, since the value 1 adopted by default in a first step is suitable only for a body of revolution. Table 9 allows to compare the experimental parameters with the calculated ones for the four ranges of Mach numbers and altitudes tested. The mean ratio between measurement and calculation being equal to 1.19 for the amplitude and to 1.22 for the period, it appears that a common coefficient $k_{L} \approx 1.20$ can be applied to Eq. (18) and (19) giving $\Delta P$ and $\Delta T$ respectively. This result is consistent with Eq. (20), with the advantage of using a single lift coefficient whose value, fairly close to 1 , is in accordance with what was expected when choosing the aircraft F-104 - see also in Fig. 16 the fall of the curve "small fighters" for small values of the lift parameter.

Remember that the lift coefficient calculated above, includes the actual value of the shape coefficient, assumed to be equal to one by default.

Table 9 Estimation of the lift coefficient $k_{L}$

\begin{tabular}{cccccccc}
\hline \hline $\begin{array}{c}\text { Mach } \\
\text { number }\end{array}$ & $\begin{array}{c}\text { Altitude } \mathrm{z} \\
(\mathrm{m})\end{array}$ & \multicolumn{2}{c}{$\Delta P(\mathrm{~Pa})$} & \multicolumn{4}{c}{$\Delta T(\mathrm{~ms})$} \\
\hline $1.15-1.30$ & $4,280-5,220$ & 147.4 & 118.7 & 1.24 & 81.5 & 65.2 & 1.25 \\
$1.30-1.40$ & $6,150-6,680$ & 99.0 & 87.6 & 1.13 & 77.0 & 63.8 & 1.21 \\
$1.40-1.55$ & $8,570-9,120$ & 72.7 & 57.0 & 1.27 & 82.9 & 66.9 & 1.24 \\
$1.55-1.70$ & $8,870-10,860$ & 63.5 & 56.8 & 1.12 & 78.2 & 66.6 & 1.17 \\
& & Average ratio & $\mathbf{1 . 1 9}$ & & & $\mathbf{1 . 2 2}$ \\
\hline \hline
\end{tabular}

Knowing the values of the shape factors of the two models given at the beginning of the paragraph, the results of the original model are easily deduced from Table 8 . Then, the lift coefficient $k_{L}$ ' for this model must be taken equal to 1.55 , by assuming that it is single and depends on the amplitude, This still plausible value according to Eq. (20) is however too small for the period.

Finally we obtain for the two models the following values of the resulting shape factors:

$$
\begin{aligned}
& k_{L}{ }^{\prime} F_{W}=0.500 \\
& k_{L} F_{W \Delta P}=0.504 \\
& k_{L} F_{W \Delta T}=0.566
\end{aligned}
$$

The Carlson's model [23-24], also called first-cut method, is laborious to implement because of the necessary graphic interpolations. We have therefore considered three representative sets of data per speed and altitude 
band. For example, for the $2^{\text {nd }}$ band, the three data pairs selected are $(M=1.30, z=6,150 \mathrm{~m}),(M=1.35, z=$ $6,415 \mathrm{~m})$, and $(M=1.40, z=6,680 \mathrm{~m})$.

Between the boundary cases $(M=1.15, z=4,280 \mathrm{~m})$ and $(M=1.70, z=10,850 \mathrm{~m})$, the specific parameters of Eq. (22) and (23) vary as follows:

$$
\begin{aligned}
& 1.023 \leq K_{P} \leq 1.052 \\
& 0.532 \leq L^{3 / 4} K_{S} \leq 0.550 \\
& 328.3 \leq c_{z} / K_{T} \leq 341.2
\end{aligned}
$$

The term $L^{3 / 4} K_{S}$ is to compare with the resulting shape factors of Eq. (25), the ratio $K_{T} / c_{z}$ is reversed here to highlight the limits of the sound speed $c_{0}$ - see Eq. (24).

Table 10 summarizes, for every band of speed and of altitude (not indicated here), the experimental results (Exper.) and the simulation results from the improved model (I. mod.), the original model (O. mod.), and the Carlson's model $(C$. mod.). Since every model is empirically adjusted on measurements of sonic booms stemming from aircraft F-104, the agreement of the average amplitudes is therefore not surprising. On the other hand, the small dispersion of the differences between calculation aud measurement, 6 to $7 \%$ for the amplitude, 2 to $3 \%$ for the period, shows that the speed and altitude parameters are accurately taken into account by the models.

Concerning the amplitude, the three models give remarkably consistent results per speed range, whether they are stronger or weaker than the measurement results. As for the period, only the results from the improved model remain close to the experiment, while those from the original model and the Carlson's model are too short $(-12 \%)$ but remain coherent. The explanation is that only the improved model has a shape factor for the period different from the shape factor for the amplitude. However, it is obvious that the original model based on Eq. (6) is poorly adapted to elongated bodies.

Table 10 Experimental and numerical sonic boom parameters

\begin{tabular}{cccccccccc}
\hline \hline $\begin{array}{c}\text { Mach } \\
\text { number }\end{array}$ & Exper. & \multicolumn{3}{c}{$\Delta P(\mathrm{~Pa})$} & \multicolumn{5}{c}{$\Delta T(\mathrm{~ms})$} \\
\hline & & & & & & & \\
$1.15-1.30$ & 147.4 & 142.8 & 141.0 & 139.8 & 81.5 & 78.2 & 68.9 & 70.6 \\
$1.30-1.40$ & 99.0 & 105.1 & 104.1 & 104.8 & 77.0 & 76.6 & 67.5 & 69.2 \\
$1.40-1.55$ & 72.7 & 68.4 & 67.7 & 71.5 & 82.9 & 80.3 & 70.7 & 72.5 \\
$1.55-1.70$ & 63.5 & 68.2 & 67.5 & 69.5 & 78.2 & 79.9 & 70.4 & 70.5 \\
& & & & & & & & & \\
Average difference & +1.1 & +0.1 & +2.1 & $\%$ & & -1.4 & -13.1 & -11.5 \\
Standard-dev. $\sigma_{\mathrm{n}-1}$ & 6.6 & 6.6 & 6.7 & $\%$ & & 2.8 & 2.5 & 1.8 \\
\hline \hline
\end{tabular}

In conclusion, it is interesting to notice that Eq. (9) becomes, in the improved formalism:

$$
\frac{\Delta P}{\Delta T}=P_{O} c_{O} \frac{\gamma}{(\gamma+1)} \sqrt{1-\frac{1}{M^{2}}}\left(\frac{R}{L}\right)^{1 / 4} \frac{1}{r}
$$

in a homogeneous atmosphere, and without taking the reflection coefficient into account. But it is also possible to calculate a mean ratio $\Delta P / \Delta T$ at ground level from the measurements and the simulations of 37 sonic booms from the F-104 Starfighter. We obtain 1,189 and 1,221 respectively, which can be considered as a significant result. 


\section{Conclusion}

The theory of ballistic wave, developed by Du Mond and Whitham among others, is already old but still in use today, in particular in the context of applications aiming to determine the path of small-caliber projectiles. The formalism used to characterize the aerodynamic behavior of projectiles moving at a supersonic speed however includes a critical point that makes its application difficult. Indeed, for many shapes of real projectiles, problems arise for calculating Whitham's function and the shape factor resulting from its integral. To our knowledge, those problems are more often than not ignored or omitted in the literature, and the few calculation results published until now appear incomplete, uncertain and sometimes contradictory.

For some profiles of projectile nose defined by their algebraic equations, it is possible to calculate analytically and numerically a reduced shape factor, so called shape coefficient. In the case of pointed shapes for which Whitham's theory was developed, the shape coefficient remains close to one, a value that seems often adopted in the literature by default and for lack of better. In contrast, in some cases of round-tipped shapes, calculation can lead to aberrant results, too small or of the domain of imaginary numbers, what cannot tally with any reality in physics. As blunt and round-tipped projectiles exist in practice, we have to admit that the theoretical calculation of the shape coefficient is not sufficiently reliable and that this factor must be set in an empirical way, the value 1 still seeming the most realistic, with an uncertainty that can be estimated at $\pm 15 \%$.

In the logic of this study on calculating the ballistic wave parameters, we have been led to take into account the ogival length and the overall length of a given projectile separately. Such an approach is implicit in the classic theory perhaps for historical reasons, since the geometric proportions of bullets and shells are always more or less standard. Therefore, the fact of comparing the improved model and the original model with experimental results cannot highlight decisive progress in such cases, but does not deny the validity of the changes made.

In order to test the improved formalism of ballistic wave at a very different scale (sonic boom), we have examined the case of the atmospheric reentry of the Apollo Command Module, a spacecraft that has a simple and symmetrical geometric shape. It appears that the classic models based on Whitham's theory cannot simulate accurately both the amplitude and the period of the sonic booms recorded at sea level, because they use a single shape factor for these two parameters. In contrast, the simulation appears more satisfactory with the improved model that uses two distinct shape factors for calculating the amplitude and the period of the sonic boom. However, this example constitutes a borderline case in regard to the usual application domain of Whitham's theory.

Finally, in order to validate the latter model in more frequent and significant cases, it was then necessary to perform simulations of sonic boom stemming from flying objects of elongated shape. Apart from a solely numerical case concerning a theoretical rocket shape, flight tests carried out with a fighter Lockheed F-104 in horizontal flight have been chosen. The simulations included the previous models and the so called first-cut method often used in such applications. Knowing that the three models have been adjusted according to the aircraft type used, the conclusions are identical to those obtained with the blunt and short body of the previous case.

Other checks of the improved model could be made using data from rockets or heavy gun projectiles, but the improvement of the theory can mainly come from CFD simulations with simple shapes of flying body, as done in the present paper. Future research could concern very short or very long shapes, and in general the effect of the length on the parameters of the ballistic wave. The question of a more precise calculation of the shape coefficient by means of analytical or numerical methods also remains open.

\section{Appendix A: Shape coefficient (pointed shapes)}

\section{A1. Analytical and numerical formalism}

Let us consider a body of total length $L$, of ogival length $H$ and of maximum radius $R$ (Fig. 3). The symmetry of revolution allows us to define the curvature of the nose under the form $y=f_{(x)}$ in a plane $(x O y)$. For calculating the shape coefficient $k_{s}$ of the body, we consider variables $x$ and $y$ reduced according to $H$ and $R$ respectively. The shape coefficient is then defined by the equation:

$$
k_{S}=\left[\int_{0}^{1} d s \frac{1}{2 \pi} \int_{0}^{s} \frac{S^{\prime \prime}{ }_{(x)}}{\sqrt{s-x}} d x\right]^{1 / 2}
$$

knowing that the shape factor of the body is given by:

$$
F_{W}=k_{S} \frac{R}{H^{1 / 4}}
$$

Note that this process is not possible in some cases, for instance when the function $f_{(x)}$ includes angular data such as the slope of the tip of the body that is implicitly related to $R$ and $H$. 


\section{A2. Algebraic and numerical calculations}

The algebraic double integration of Eq. (a1) calls in general on classic integration formulas [62], sometimes on more complex formulations such as the Fresnel's integrals or the elliptic integrals [64]. In Table A1, we give the equation $y=f_{(x)}$ of the curve generating every shape. Of course the second derivative $S^{\prime \prime}{ }_{(x)}$ of Eq. (a1) is deduced from the cross section $S_{(x)}=\pi y^{2}$.

It was also interesting to confirm the algebraic results with the help of a numerical calculation. This one is made difficult by the particular form of Whitham's function: to avoid a numerical problem for the critical value $x$ $=s$, the idea is to replace the upper limit $s$ of the integral by a limit $(s-\varepsilon), \varepsilon$ being a small number.

Considering Eq. (a1) where $0 \leq s \leq 1$, we discretize the interval $[0 ; 1]$ into $n$ values $s_{j}=j / n$ with $1 \leq j \leq \mathrm{n}$. Assuming that Whitham's function $F_{(s)}$ is zero at the origin $s_{0}=0$, its successive values are then approached by:

$$
F_{\left(s_{j}\right)}=\frac{1}{2 \pi} \frac{s_{j}-\varepsilon}{m \cdot j} \sum_{i=1}^{m . j} \frac{1}{2}\left[\frac{S^{\prime \prime}{ }_{\left(x_{i}\right)}}{\sqrt{s_{j}-x_{i}}}+\frac{S^{\prime \prime}{ }_{\left(x_{i-1}\right)}}{\sqrt{s_{j}-x_{i-1}}}\right]
$$

where $m$ is a parameter allowing to adapt the number of steps $\Delta x=x_{i}-x_{i-1}$ to the width of every interval $\left[0 ; s_{j}\right]$. The shape coefficient is next given by the summation:

$$
k_{S}=\left[\frac{1}{n} \sum_{j=1}^{n} \frac{1}{2}\left[F_{s_{j}}+F_{s_{j-l}}\right]\right]^{1 / 2}
$$

Table A1 Shape coefficients $k_{S}$ resulting from pointed geometric shapes

\begin{tabular}{cccccc}
\hline $\begin{array}{c}\text { Shape } \\
\mathbf{N}^{\circ}\end{array}$ & Equation & Definition & $\begin{array}{c}\text { Algebraic } \\
\text { result }\end{array}$ & $\begin{array}{c}\text { Numerical } \\
\text { Result }\end{array}$ & $\begin{array}{c}\text { Difference } \\
(\%)\end{array}$ \\
\hline 1 & $y=1-(1-x)^{3}$ & $3^{\text {rd }}$ degree & 0.809040 & 0.807295 & -0.22 \\
2 & $y=\operatorname{sqrt}\left(4-3(x-1)^{2}\right)-1$ & ellipse & 0.849770 & 0.847978 & -0.21 \\
3 & $y=2 x-x^{2}$ & parabola & 0.872871 & 0.871031 & -0.21 \\
4 & $y=\sin (\pi x / 2)$ & sinusoid & 0.890519 & 0.888647 & -0.21 \\
5 & $y=\operatorname{sqrt}\left(3 x^{2}-2 x^{3}\right)$ & polynomial & 0.894427 & 0.892567 & -0.21 \\
6 & $y=\operatorname{sqrt}(x)$ & parabola & 1.000000 & 1.001698 & +0.17 \\
7 & $y=\operatorname{sqrt}(3 x / 2+1 / 16)-1 / 4$ & parabola & 1.039566 & 1.037872 & -0.16 \\
8 & $y=x$ & cone & 1.154700 & 1.153029 & -0.14 \\
\hline \hline
\end{tabular}

This integration method is very simple but enables us to perform a quick calculation which is precise enough to check a sometimes complex algebraic integration: in the examples of Table A1, with the parameters $n=1000$, $m=10$ and $\varepsilon=10^{-6}$, the relative error compared to the exact result indeed varies between 0.1 and $0.2 \%$.

Shape $\mathrm{N}^{\circ} 1$ is quoted as a bullet shape in Ref. $[9,13,28]$, shape $\mathrm{N}^{\circ} 5$ is given as a typical shell shape in Ref. [8]. Round-tipped shape $\mathrm{N}^{\circ} 6$ is here considered as the limit of a pointed shape such as shape $\mathrm{N}^{\circ} 7$ : in this case, the algebraic and numerical calculation methods are specific since $S{ }^{\prime \prime}{ }_{(x)}=0$ except for $x=0$ (see Appendix B).

It seems that the only result of Table A1 that can be found in the literature is that of the cone [15]. It is unfortunate that the numerical method presented in Ref. [14] does not include Whitham's integral of Eq. (2) and therefore does not give any practical result regarding the shape factor.

Figure A1 $(\mathrm{a}, \mathrm{b}, \mathrm{c})$ gives the nose shapes from Table A1, except Whitham's polynomial shape $\mathrm{N}^{\circ} 5[8]$ that is very close to the sinusoid shape $\mathrm{N}^{\circ} 4$. Curves $\mathrm{N}^{\circ} 1,3$ and 4 chosen in Fig. (a) have a common horizontal tangent at $x=1$. Curves $\mathrm{N}^{\circ} 1,2$ and 7 chosen in Fig. (b) have a common tangent at $x=0$. The rounded values of the shape coefficients are coherent and increase when the shape becomes closer to the cone $\mathrm{N}^{\circ} 8$ of Fig. (c), that also includes curves $\mathrm{N}^{\circ} 6$ and 7.

We can notice in Table A1 that all the shape coefficients $k_{s}$ are within the range $1 \pm 0.2$. 


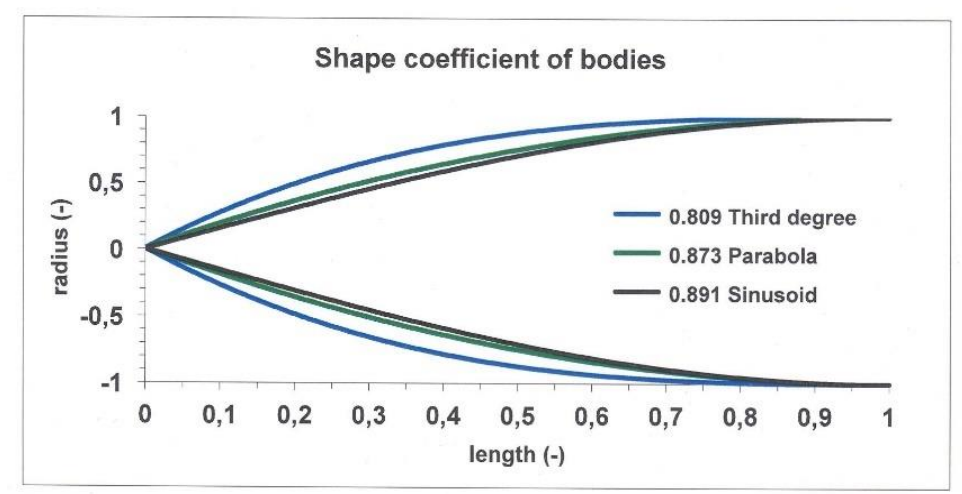

(a)

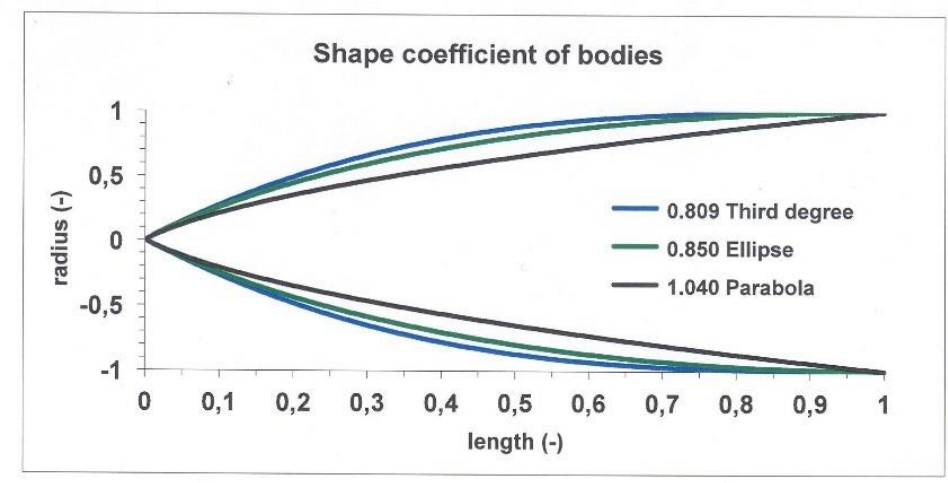

(b)

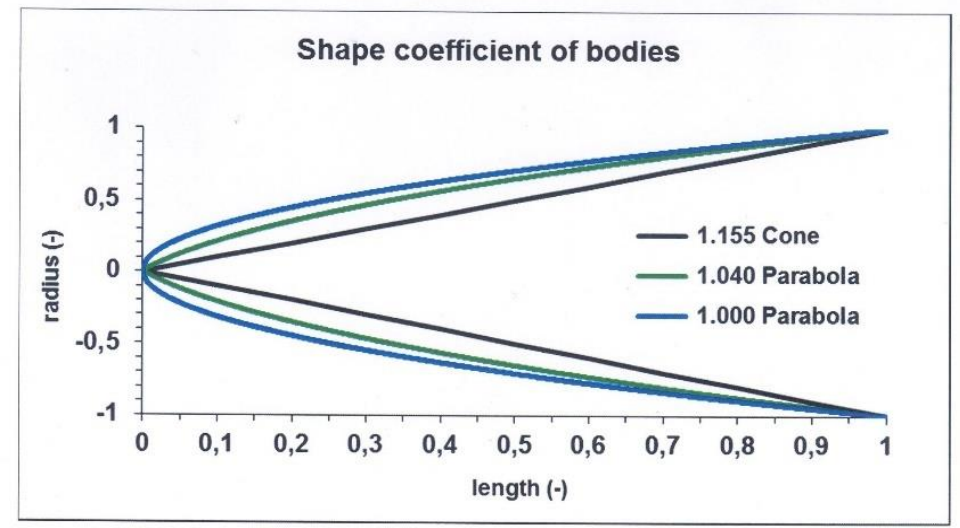

(c)

Fig. A1 Nose shapes and shape coefficients of some pointed bodies.

\section{Appendix B: Shape coefficient (round-tipped shapes)}

\section{B1. Parabolic shapes}

The equation of parabola shape $\mathrm{N}^{\circ} 6$ in Table A1 leads to a second derivative $S^{\prime \prime}{ }_{(x)}$ equal to zero, as $S_{(x)}=\pi \cdot x$, except for $x=0$ where it is infinite because of the discontinuity of the first derivative. Therefore, Whitham's function of Eq. (1) is nil or infinite and it is reasonable to consider that the shape factor of the body is indeterminate. However, here we consider its round-tipped shape as the limit of a pointed parabolic shape.

Given a parabola of tip $\mathrm{S}$ coming through the origin $\mathrm{O}$ and the point $[H ; R]$. The rotation around $\mathrm{Ox}$ of the arc of parabola beyond $\mathrm{O}$ (blue part in Fig. B1) generates a volume (V) such as the pointed shape $\mathrm{N}^{\circ} 7$ in Table A1. Note that if $\mathrm{S}$ tends to $\mathrm{O}$, the shape of revolution $(\mathrm{V})$ tends to the round-tipped parabola shape $\mathrm{N}^{\circ} 6$. 


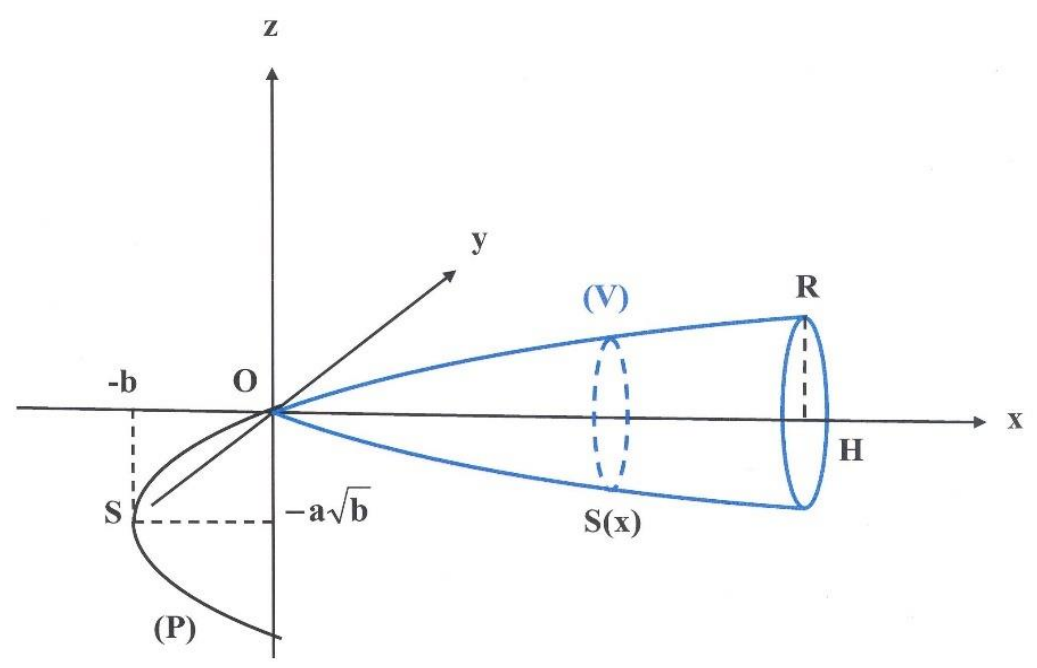

Fig. B1 Pointed body generated by an arc of parabola.

With the notations of Fig. B1 we have the following equations successively:

$$
\begin{aligned}
& y=a \sqrt{x+b}-a \sqrt{b} \\
& S_{(x)}=\pi y^{2} \\
& S_{(x)}^{\prime \prime}=\pi a^{2} \frac{\sqrt{b}}{2} \frac{1}{(x+b)^{3 / 2}} \\
& F_{(s)}=\frac{a^{2} \sqrt{b}}{4} \int_{0}^{s} \frac{d x}{(x+b)^{3 / 2} \sqrt{s-x}}
\end{aligned}
$$

This integral can be solved with a general formula from Ref. [62] or by using a double change of variable, namely $X=x+b$ and $u=(s+b) / X-1$, which enables us to write Eq. (b4) under the form:

$$
F_{(s)}=\frac{a^{2} \sqrt{b}}{4(s+b)} \int_{0}^{s / b} \frac{d u}{\sqrt{u}}=\frac{a^{2} \sqrt{s}}{2(s+b)}
$$

According to a formula from Ref. [62], integration of Eq. (b5) in interval [0 ; H] finally gives the shape factor:

$$
F_{W}=\left[a^{2} \sqrt{H}\left(1-\sqrt{\frac{b}{H}} \arctan \sqrt{\frac{H}{b}}\right)\right]^{1 / 2}
$$

that allowed us to calculate the shape coefficient of pointed shape $\mathrm{N}^{\circ} 7$ of Table A1 (algebraic result).

When parameter $b$ tends to zero, $\mathrm{S}$ tends to $\mathrm{O}$ and we have:

$$
\begin{aligned}
& a \rightarrow R / \sqrt{H} \\
& F_{W} \rightarrow R / H^{1 / 4}
\end{aligned}
$$

Therefore, $k_{s}=1$ is the searched shape coefficient for round-tipped shape $\mathrm{N}^{\circ} 6$ of Table A1.

In fact, the same algebraic result is reached more easily by making directly $b=0$ in Eq. (b5).

Since we have generally $S^{\prime \prime}{ }_{(x)}=0$ in this case, the numerical integration method of Appendix A cannot be used. Yet we can discretize the body shape into $n$ cone frustums of constant width $h$ (Fig. B2), by assuming that Whitham's integral of the shape can be obtained step by step from the elementary Whitham's functions $F_{i}(s)$ calculated for every truncated cone of constant slope $a_{i}$. 


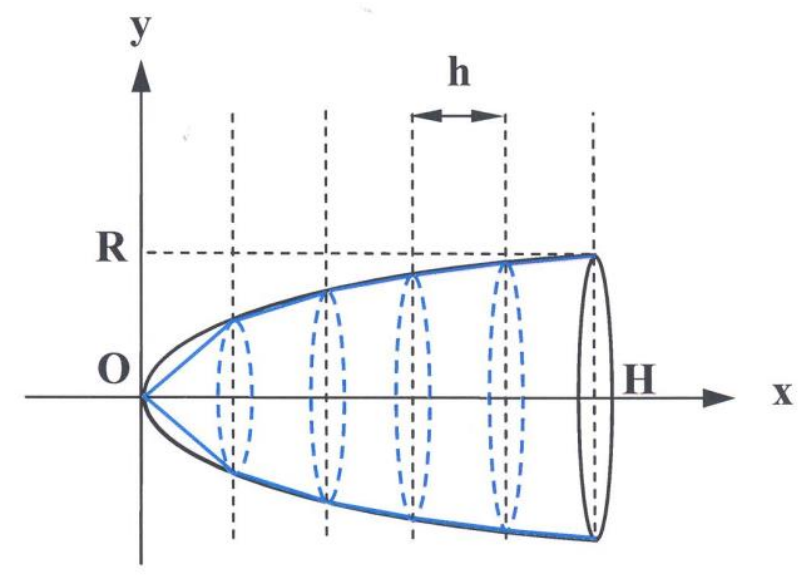

Fig. B2 Discretization of a body shape by cone frustums.

For every cone frustum, the second derivative of the cross-section is $S^{\prime \prime}{ }_{(x)}=2 \pi a_{i}{ }^{2}$. The elementary Whitham's function and the resulting Witham's integral are then written:

$$
\begin{aligned}
& F_{i(s)}=\int_{0}^{s} \frac{a_{i}^{2}}{\sqrt{s-x}} d x \\
& I_{W}=\sum_{i=1}^{n} \int_{x_{i-1}}^{x_{i}} d s \int_{0}^{s} \frac{a_{i}^{2}}{\sqrt{s-x}} d x
\end{aligned}
$$

Double integration then leads to the shape factor:

$$
F_{W}=\left[\frac{4}{3} \sum_{i=1}^{n} a_{i}^{2}\left(x_{i}^{3 / 2}-x_{i-1}^{3 / 2}\right)\right]^{1 / 2}
$$

in which we recognize the shape coefficient of a simple cone.

Note that a more complex and precise integration method using polynomial segments is described in Ref. [14-15], but this method only deals with the calculation of Whitham's function.

In fact, Eq. (b10) accurately applies to the cases where Whitham's function remains positive or zero in the interval, which is the case for all the pointed bodies defined by Eq. (b1) such as shape $\mathrm{N}^{\circ} 7$ of Table A1. For the round-tipped parabolic shape $\mathrm{N}^{\circ} 6$, the convergence is slower because of the infinite slope of the tangent at the origin, but it is easy to demonstrate that the theoretical limit of the summation is 1 when $n$ tends to infinite, which is also shown by Eq. (b7). The numerical result $k_{S} \approx 1.0017$ given in Table A1 corresponds to $\mathrm{n}=50,000$.

\section{B2. Hyperbolic and elliptic shapes}

Consider the following equation where $m$ is an arbitrary parameter:

$$
y=\frac{R}{H}\left[\left(2 \frac{H}{R} m-1\right) x^{2}+2 H\left(1-\frac{H}{R} m\right) x\right]^{1 / 2}
$$

It can be shown that the body of revolution of tip $\mathrm{O}$ generated by the curve defined by this equation has as a shape factor equal to:

$$
F_{W}=\sqrt{\frac{4}{3}} \frac{R}{H^{1 / 4}} \sqrt{2 \frac{H}{R} m-1}
$$

It is interesting to notice that $m$ represents here the slope of the tangent at the point $[H ; R]$ of the curve. In practice, we can adopt the normalized equations below by making $R=H=1$ in Eq. (b9) and (b10):

$$
y=\left[(2 m-1) x^{2}+2(1-m) x\right]^{1 / 2}
$$




$$
k_{S}=\sqrt{\frac{4}{3}} \sqrt{2 m-1}
$$

In Table B1, the different curves and their shape coefficients $k_{S}$ are defined by Eq. (b11) and (b12) according to values of $m$ taken in the interval $[0 ; 1]$. In the examples given in Table B2, the shape coefficients are also calculated numerically with the help of Eq. (a3) and (a4). The corresponding curves are represented in Fig. B3.

Table B1 Domain of definition of conic sections

\begin{tabular}{ccc}
\hline \hline Parameter & Curve & $k_{S}$ \\
\hline$m=1$ & cone & 1.1547 \\
$0.5<m<1$ & hyperbola & real $>0$ \\
$m=0.5$ & parabola & 0 \\
$0<m<0.5$ & ellipse & imaginary $>0 \mathrm{i}$ \\
$m=0$ & ellipse & $1.1547 \mathrm{i}$ \\
\hline \hline
\end{tabular}

It is clear that too small values and imaginary values of the shape coefficient have no sense in physics, since a body "perfectly penetrating" into air does not exist in all likelihood. Thus, the theory seems to be in fault for some of the chosen shapes, even when the integration result is plausible (hyperbola, shape $\mathrm{N}^{\circ} 2$ ). Moreover, the correlation between rounded tip and aberrant result is not proved, the integrals being defined despite the singularity at $\mathrm{x}=0$. This is unfortunate, since numerous bullets, shells, aircraft, rockets or other supersonic objects have rounded, flattened or truncated noses.

Table B2 Shape coefficients $k_{S}$ resulting from round-tipped geometric shapes

\begin{tabular}{cccccr}
\hline \hline $\begin{array}{c}\text { Shape } \\
\mathbf{N}^{\circ}\end{array}$ & Equation & Definition & $\begin{array}{c}\text { Algebraic } \\
\text { result }\end{array}$ & $\begin{array}{c}\text { Numerical } \\
\text { result }\end{array}$ & $\begin{array}{c}\text { Difference } \\
(\%)\end{array}$ \\
\hline 1 & $y=x$ & cone & 1.154700 & 1.153029 & -0.14 \\
2 & $y=\operatorname{sqrt}\left(x^{2} / 2+x / 2\right)$ & hyperbola & 0.816496 & 0.815315 & -0.14 \\
3 & $y=\operatorname{sqrt}\left(x^{2} / 3+2 x / 3\right)$ & hyperbola & 0.384900 & 0.384343 & -0.14 \\
4 & $y=\operatorname{sqrt}(x)$ & parabola & 0.000000 & 0.000000 & 0.00 \\
5 & $y=\operatorname{sqrt}\left(-x^{2} / 2+3 x / 2\right)$ & ellipse & $0.816496 \mathrm{i}$ & $0.815315 \mathrm{i}$ & -0.14 \\
6 & $y=\operatorname{sqrt}\left(2 x-x^{2}\right)$ & ellipse & $1.154700 \mathrm{i}$ & $1.153029 \mathrm{i}$ & -0.14 \\
\hline \hline
\end{tabular}

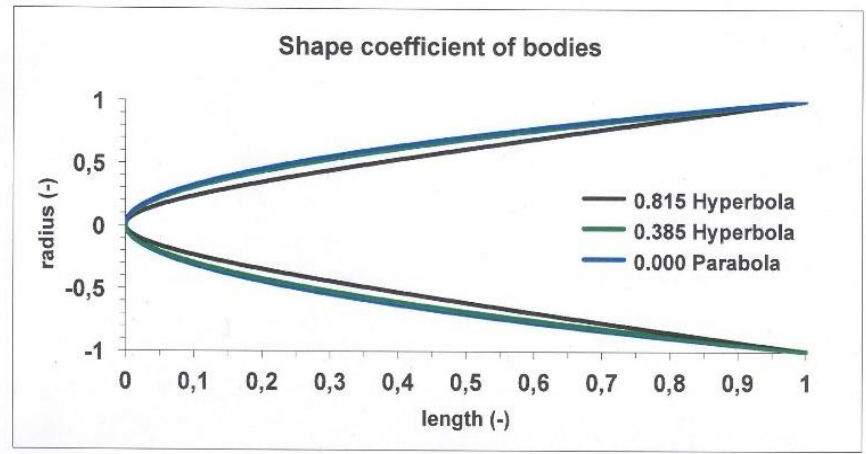

(a) 


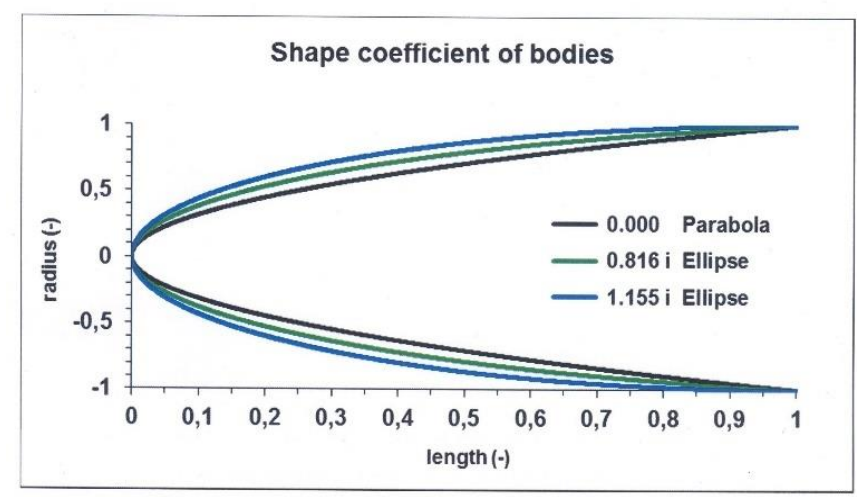

(b)

Fig. B3 Nose shapes and shape coefficients of some round-tipped bodies.

We can also remark that the shape coefficient of the round-tipped parabola shape is equal to 1 (Table A1) or equal to 0 (Table B2) according to the calculation mode, as it is sometimes the case for limits "on the left" and "on the right" of some algebraic functions. Thus, this shape may be at the very borderline of the domain of validity of Whitham's theory.

On the other hand, it should be noted that Eq. (b10) gives, for all the shapes of Tables A1 and B2, positive and real shape coefficient values such as:

$$
1 \leq k_{S} \leq 1.1547
$$

We can reasonably assume that theses "approximate" values are at least as realistic as the "accurate" values given in Table B2. The question remains open for shapes $\mathrm{N}^{\circ} 1$ to 5 of Table A1 where the accurate values of the shape coefficient do not agree with Eq. (b13).

\section{Appendix C: Sonic boom calculations}

\section{C1. Influence of the geometry of a body on the $\mathrm{N}$-wave parameters}

In order to check the influence of the general shape of a body on the $\mathrm{N}$-wave parameters (amplitude $\Delta P$ and period $\Delta T$ ), simulations were carried out with a body of varied dimensions and proportions flying in altitude (at a height of $8 \mathrm{~km}$ over sea level with a Mach number of 1.7 in our example). The configurations of the body are summarized in columns 1 and 2 of Table $\mathrm{C} 1$ : the ogival length $H$ of the body remaining unchanged for a given radius, the different lengths are obtained by modifying only the cylindrical length.

Table C1 Proportions of bodies, N-wave parameters (els $A+$ TRAPS)

\begin{tabular}{ccccc}
\hline \hline $\begin{array}{c}\text { Length } \\
(\mathrm{x} L)\end{array}$ & $\begin{array}{c}\text { Radius } \\
(\mathrm{x} R)\end{array}$ & $\begin{array}{c}\Delta P^{+} \\
(\mathrm{Pa})\end{array}$ & $\begin{array}{c}\Delta P^{-} \\
(\mathrm{Pa})\end{array}$ & $\begin{array}{c}\Delta T \\
(\mathrm{~ms})\end{array}$ \\
\hline 0.6 & 1 & 45.2 & -41.4 & 41.6 \\
1 & 1 & 45.1 & -44.0 & 45.3 \\
1.4 & 1 & 46.0 & -40.9 & 51.3 \\
1.2 & 2 & 76.4 & -66.1 & 68.2 \\
2 & 2 & 75.7 & -69.0 & 80.0 \\
2.8 & 2 & 77.5 & -67.7 & 91.7 \\
\hline \hline
\end{tabular}

The velocity and pressure fields of the aerodynamic wake are calculated in the vicinity of the body using the CFD code $e l s A$ (Fig. C1). For calculating the $\mathrm{N}$-wave, pressure profiles parallel to the trajectory are propagated as far as sea level in US standard atmosphere, using the nonlinear propagation code TRAPS [25] (Fig. C2-C3). Let us note that the N-waves resulting from the computing chain elsA + TRAPS are not completely symmetric, as it is often the case in reality: see columns $\Delta P^{+}$(overpressure) and $\Delta P^{-}$(under-pressure) in Table $\mathrm{C} 1$. 


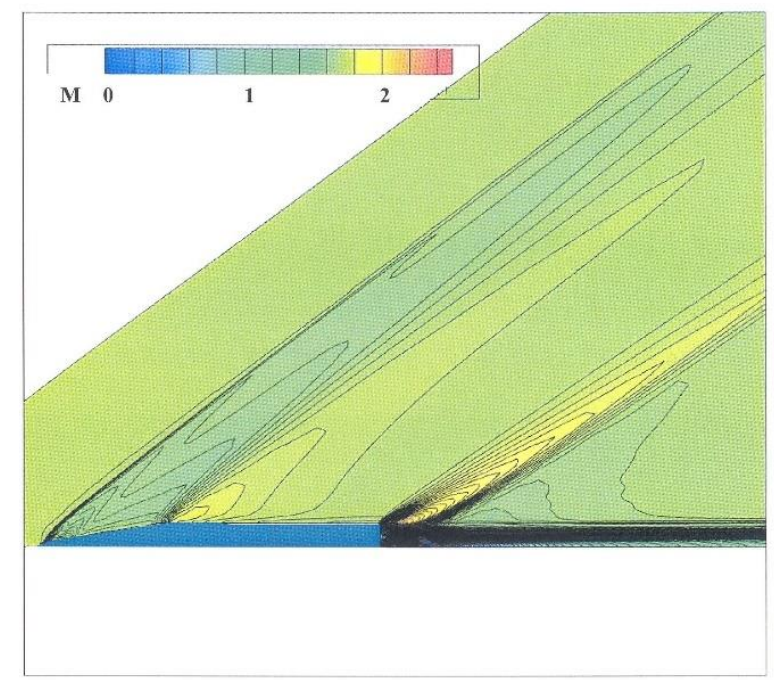

Fig. C1 Aerodynamic wake of a supersonic object: Mach number contours.

Analyses are made by comparing the $\mathrm{N}$-wave parameters obtained in various configurations of shape, altitude and Mach number. For a scaling ratio $k$, amplitude $\Delta P$ and period $\Delta T$ must vary according to a law in $k^{3 / 4}$ according to the shape factor stemming from Eq. (6) or (13): for instance, columns 3 to 5 of Table $\mathrm{C} 1$ show an average overpressure increase in $2^{0.72}$ and an average period increase in $2^{0.80}$ when radius and length are multiplied by two $(k=2)$.

Furthermore, in Table C1, when only the cylindrical length of the body varies, and hence its total length for a given radius:

- the average standard deviation of amplitude is $\pm 2 \%$

- the period varies in $L^{0.25}$ for $R=1$, in $L^{0.35}$. for $R=2$.

Thus, the amplitude remains almost constant as suggested by Whitham's formalism, but that is obviously not the case for the period: the present results and the others in various configurations of altitude and Mach number suggested us to assume a law in $L^{1 / 4}$ for the period that seems consistent with the rest of the formalism.

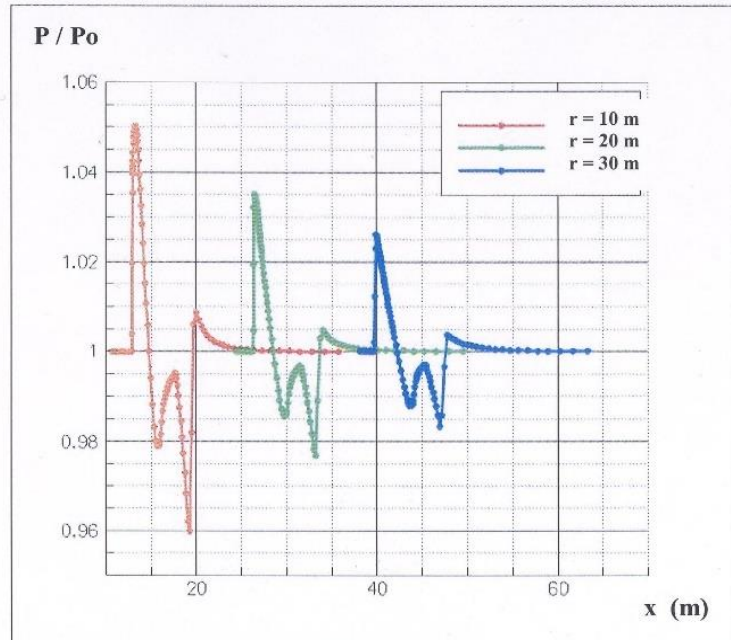

Fig. C2 Pressure profiles calculated at several distances from the flight path. 


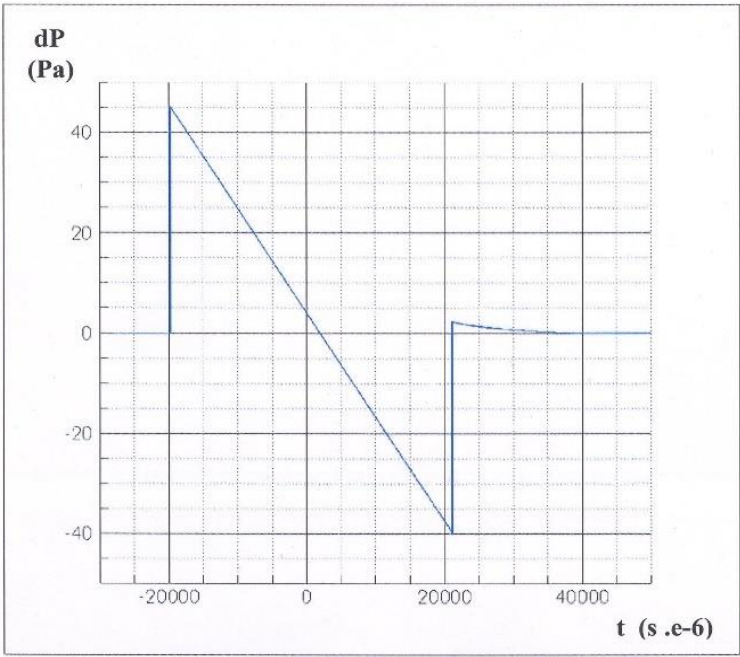

Fig. C3 N-wave calculated at sea level $\left(\mathrm{dP}=\mathrm{P}-\mathrm{P}_{\mathbf{0}}\right)$.

\section{C2. Calculation of the $\mathrm{N}$-wave parameters in a non-homogeneous atmosphere}

A classic difficulty to apply the formalism of the ballistic wave to the sonic boom of large-sized bodies in flight is related to the fact that Eq. (4) and Eq. (8) giving $\Delta P$ and $\Delta T$ respectively are only suitable in a homogeneous atmosphere, namely at the flight altitude $z$, while the listening point is generally on the ground or at sea level.

Let us consider two points $\mathrm{M}_{\mathrm{z}}$ and $\mathrm{M}_{0}$ located at the same distance $r$ from the flight path, the first at the same altitude as the flying object (index $z$ ), the second at another altitude (index 0 ). These points differ by the ambient conditions of atmospheric pressure and sound speed, $\left(P_{z}, c_{z}\right)$ for $\mathrm{M}_{\mathrm{z}},\left(P_{0}, c_{0}\right)$ for $\mathrm{M}_{0}$. The $\mathrm{N}$-wave parameters $\Delta P_{z}$ and $\Delta T_{z}$ at $\mathrm{M}_{\mathrm{z}}$ can be calculated from Eq. (4) and (8), knowing the Mach number $M$ of the flying object at altitude $z$. Assuming now that the $\mathrm{N}$-wave of parameters $\Delta P_{0}$ and $\Delta T_{0}$ at $\mathrm{M}_{0}$ has the same acoustic energy and the same wavelength as the $\mathrm{N}$-wave calculated at $\mathrm{M}_{\mathrm{z}}$, we easily obtain the following "transformation formulas" for calculating these parameters:

$$
\begin{aligned}
& \Delta P_{0}=\Delta P_{z} \sqrt{\frac{P_{0}}{P_{z}}} \\
& \Delta T_{0}=\Delta T_{z} \frac{c_{z}}{c_{0}}
\end{aligned}
$$

These equations have been tested and validated in standard atmosphere with the help of the TRAPS propagation code [25]. They are obviously uncertain when the listening point is very distant from the flight path of the flying object, but they probably constitute an acceptable solution when the meteorology of the day is poorly known, what often occurs in practice. In addition, they are implicitly applied in the Carlson's "first-cut method" developed for the sonic boom of airplanes [23-24].

\section{Acknowledgments}

The authors greatly appreciate Dr Philippe Delorme, Dr Jean-Luc Akian, Research Engineers, Dr Christian Musso, Senior Scientist, and Dr. Jean-Luc Vérant, Head of Research Unit TACT, ONERA, France, as well as Mr François Baldeschi, Product Manager, SECAPEM, France, and Mr Alexandre Alexieff, Consultant Engineer, so as Hon. Robert Acton, for their helpful collaboration.

\section{References}

[1] Mach, E., "Photographische Fixierung der durch Projectile in der Luft eingeleiteten Vorgänge", Akademie der Künsten und Wissenschaften, Vienna, Austria, 1887.

[2] Cranz, C., Lehrbuch der Ballistik, Volume 1, $2^{\text {nd }}$ Edition, Germany, 1917. 
[3] Becker, R., "Stosswellen und Detonationen", Zeitung für Physik 8, Germany, 1921, pp. 321-347.

[4] Charbonnier, P., Esclangon, E., "Etude cinématique du champ acoustique d'un projectile. L'acoustique des canons et des projectiles", Mémorial de l'Artillerie Française, tome IV, 3ème fascicule, France, 1925.

[5] Landau, L.D., "On shock waves at large distances from the place of their origin", J. Phys. Acad. Sciences 9, USSR, 1945, pp. 496-505.

[6] Du Mond, J.W.M., Cohen, E.R., Panofsky, W.K.H., and Deeds, E., "A determination of the wave forms and laws of propagation and dissipation of ballistic shock waves”, J. Acoust. Soc. Am., Vol. 18, No. 1, July 1946, pp. 97-118. DOI: $10.1121 / 1.1916347$

[7]Lighthill, M.J., "Supersonic flow past slender bodies of revolution the slope of whose meridian section is discontinuous", The Quarterly Journal of Mechanics and Applied Mathematics, Vol. 1, No. 1, 1948, pp. 90-102. DOI: $10.1093 /$ qjmam/1.1.90

[8] Whitham, G.B., "The behaviour of supersonic flow past a body of revolution, far from the axis ", Proceedings of the Royal Society of London, Serie A, 201, March 1950, pp. 89-109.

DOI: $10.1098 /$ rspa.1950.0045

[9] Whitham, G.B., "The flow pattern of a supersonic projectile", Communications on pure and applied mathematics, Vol. V, No. 3, August 1952, , pp. 301-348.

DOI: $10.1002 /(I S S N) 1097-0312$

[10] Whitham, G.B., "On the propagation of weak shock waves", Journal of Fluid Mechanics, Vol. 1, No. 3, 1956, pp. 290-318. DOI: $10.1017 / \mathrm{S} 0022112056000172$

[11] Ryhming, I. L., "The supersonic boom of a projectile related to drag and volume", Journal of the Aerospace Sciences, Vol. 28, No. 2, February 1961, pp. 113-118. DOI: $10.2514 / 8.8886$

[12] Middleton, W. D., and Carlson, H.W., "A numerical method for calculating near-field sonic boom pressure signatures", NASA TN D-3082, November 1965.

ID: 19660001041

[13] Whitham, G.B., Linear and nonlinear waves, Pure and Applied Mathematics, John Wiley and Sons, Inc., New-York, U.S.A., 1974, Chapter 9, pp. 312-338.

[14] Ritzel D.V., Gottlieb J.J., "Numerical evaluation of Whitham's F-function for supersonic projectiles", AIAA Journal, Vol. 26, No. 2, February 1988, pp. 244-247.

DOI: $10.2514 / 3.9880$

[15] Gottlieb, J.J., Ritzel, D.V., "Analytical study of sonic boom from supersonic projectiles", Progresses in Aerospace Sciences, Vol. 25, No. 2, 1988, pp. 131-188.

DOI: 10.1016/0376-0421(88)90006-1

[16] Stoughton, R., "Measurements of small-caliber ballistic shock waves in air", J. Acoust. Soc. Am., Vol. 102, No. 2, Part 1, August 1997, pp. 781-787.

DOI: $10.1121 / 1.419904$

[17] Sadler, B.M., Pham, T., Sadler, L.C., "Optimal and wavelet-based shock wave detection and estimation", J. Acoust. Soc. Am., Vol. 104, No. 2, August 1998, pp. 955-963.

DOI: $10.1121 / 1.423312$

[18] Kanamori, M., Suzuki, K., "Three-dimensional shock wave detection based on the theory of characteristics", AIAA Journal, Vol. 51, No. 9, September 2013, pp. 2126-2132.

DOI: 10.2514/1.J051922

[19] Muthukumaran, C.K., Rajesh, G., Kim, H.D., "Launch dynamics of supersonic projectiles", Journal of Spacecraft and Rockets, Vol.50, No. 6, November 2013, pp. 1150-1161. DOI: $10.2514 / 1 . A 32466$

[20] Walkden, F., "The shock pattern of a wing-body combination, far from the flight path", Aeronautical Quarterly, Vol. 9, No. 2, May 1958, pp. 164-194.

DOI: $10.1017 / \mathrm{S} 0001925900001372$

[21] Hayes, W.D., Haefeli, R.C., and Kulsrud, H.E., "Sonic boom propagation in a stratified atmosphere, with computer program", NASA CR-1299, April 1969.

ID: 19690013184

[22] Seebass, R., "Sonic boom theory", Journal of Aircraft, Vol. 6, No. 3, May-June 1969, pp. 177-184. DOI: $10.2514 / 3.44032$

[23] Carlson, H.W., and Maglieri, D., "Review of sonic-boom generation theory and prediction methods", J. Acoust. Soc. Am., Vol. 51, No. 2, Pt. 3, February 1972, pp. 675-685.

DOI: $10.1121 / 1.1912901$

[24] Carlson, H.W., "Simplified sonic boom prediction", NASA TP-1122, March 1978.

ID: 19780012135 1980 .

[25] Taylor, A.D., "The TRAPS sonic boom program”, NOAA TM ERL ARL-87, Air Resources Laboratories, July

[26] Darden, C.M., "Limitations of linear theory for sonic boom calculations", Journal of Aircraft, Vol. 30, N³, MayJune 1993, pp 309-314.

DOI: $10.2514 / 3.46335$

[27] Plotkin, K.J., "State of the art of sonic boom modeling", J. Acoust. Soc. Am., Vol. 111, No. 1, Pt. 2, January 2002, pp. 530-536.

DOI: $10.1121 / 1.1379075$ 
[28] Cain, T., "A correction to sonic boom theory”, The Aeronautical Journal, Vol. 113, No. 1149, November 2009, pp. 739-745.

DOI: $10.1017 /$ S0001924000003390

[29] Jung, T.P., Starkey, R.P., Argrow, P., "Modified linear theory sonic booms compared to experimental and numerical results", Journal of Aircraft, Vol.52, N 6, November 2015, pp. 1821-1837.

DOI: $10.2514 / 1 . C 033088$

[30] Lina, L.J., and Maglieri, D.J., "Ground measurements of airplane shock-wave noise at Mach numbers to 2.0 and at altitudes to 60,000 feet", NASA TN D-235, March 1960.

ID: 19860065695

[31] Hubbard, H.H., Maglieri, D.J., Huckel, V., and Hilton, D.A. (with appendix by Carlson, H.W.), "Ground measurements of sonic-boom pressures for the altitude range of 10,000 to 75,000 feet", NASA TR R-198, July 1964.

ID: 19640014910

[32] Carlson, H.W., "Correlation of sonic-boom theory with wind-tunnel and flight measurements", NASA TR R-213, December 1964.

ID: 19650002272

[33] Maglieri, D.J., Huckel, V., and Henderson, H.R., "Sonic boom measurements for SR-71 aircraft operating at Mach numbers to 3.0 and altitudes to 24,384 meters", NASA TN D-6823, September 1972.

ID: 19720023371

[34] Schaffar, M., Parmentier, G., Dancer, A., Froböse, M., "Revue et synthèse de l'ensemble des travaux effectués sur le bang sonique, en particulier à l'ISL 1961-1974”, Report 40/74, I.S.L., Saint-Louis, France, December 1974.

[35] Hubbard, H.H., Maglieri, D.J., "Sonic boom signature data from cruciform microphone array experiments during the EAFB National sonic boom evaluation program”, NASA CR-182027, May 1990.

ID: 19900012289

[36] Norris, S.R., Haering, E.A. Jr., and Murray, J.E., "Ground-based sensors for the SR-71 sonic-boom propagation experiment", NASA TM 104310, September 1995.

ID: 19960008877

[37] Ivanteyeva, L.G., Kovalenko, V.V., Pavlyukov, E.V., Teperin, L.L., and Rackl, R.G., "Validation of sonic boom propagation codes using SR-71 flight test data", J. Acoust. Soc. Am., Vol. 111, No. 1, January 2002, pp. 554-561. DOI: $10.1121 / 1.1404377$

[38] Auger, T., and Coulouvrat, F., "Numerical simulation of sonic boom focusing", AIAA Journal, Vol. 40, No. 9, September 2002, pp. 1726-1734.

DOI: $10.2514 / 2.1877$

[39] Ménéxiadis, G., and Varnier, J., "Long-range propagation of sonic boom from the Concorde airliner: analyses and simulations", Journal of Aircraft, Vol. 45, No. 5, September-October 2008, pp. 1612-1618.

DOI: $10.2514 / 1.33899$

[40] Shrout, B.L., Mack, R.J., and Dollyhigh, S.M., "A wind tunnel investigation of sonic-boom pressure distributions of bodies of revolution at Mach 2.96, 3.83, and 4.63", NASA TN D-6195, April 1971.

ID: 19710012486

[41] Hilton, D.A., Henderson, H.R., and Mc Kinney, R., "Sonic-boom ground-pressure measurements from Apollo 15", NASA TN D-6950, September 1972.

ID: 19720023246

[42] Henderson, H.R. and Hilton, D.A., "Sonic-boom ground-pressure measurements from the launch and reentry of Apollo 16", NASA TN D-7606, August 1974.

ID: 19740023384

[43] Henderson, H.R. and Hilton, D.A., "Sonic-boom measurements in the focus region during the ascent of Apollo 17", NASA TN D-7806, December 1974.

ID: 19750005520

[44] Ferri, A., Siclari, M., and Ting, L., "Sonic-boom analysis for high altitude flight at high Mach number", AIAA Paper 73-1034, Aeroacoustics Conference, Seattle, WA, U.S.A., October 1973.

DOI: $10.2514 / 6.1973-1034$

[45] Ferri, A., Ting, L., and Lo, R.W., "Nonlinear sonic-boom propagation including the asymmetric effects", AIAA Journal, Vol. 15, No. 5, May 1977, pp. 653-658.

DOI: $10.2514 / 3.60675$

[46] Ashby, G.C., Jr., "A study of the sonic-boom characteristics of a blunt body at a Mach number of 6", NASA TP 1787, December 1980.

ID: 19810005404

[47] Moss, J.N., Glass, C.E., and Greene, F.A., "DSMC simulations of Apollo capsule aerodynamics for hypersonic rarefied conditions", $9^{\text {th }}$ AIAA/ASM Thermophysics and Heat Transfer Conference, San Francisco, CA, U.S.A., June 2006. DOI: $10.2514 / 6.2006-3577$

[48] Loubeau, A., and Coulouvrat, F., "Effects of meteorological variability on sonic boom propagation from hypersonic aircraft”, AIAA Journal, Vol. 47, No. 11, November 2009, pp. 2632-2641.

DOI: $10.2514 / 1.4133$

[49] Henneton, M., Gainville, O., and Coulouvrat, F., "Numerical simulation of sonic boom from hypersonic meteoroids", AIAA Journal, Vol. 53 , No. 9, September 2015, pp. 2560-2570.

DOI: $10.2514 / 1 . J 053421$

[50] Seebass, R., and George, A.R., "Sonic boom minimization", J. Acoust. Soc. Am., Vol. 51, No. 2, Pt. 3, February 1972, pp. 686-694. 
DOI: $10.1121 / 1.1912902$

[51] Darden, C.M., "Sonic boom theory: its status in prediction and minimization", Journal of Aircraft, Vol. 14, N ${ }^{\circ}$ 6, June 1977, pp 569-576.

DOI: $10.2514 / 3.58822$

[52] Mack, R.J., Darden, C.M., "Some effects of applying sonic boom minimization to supersonic cruise aircraft design", Journal of Aircraft, Vol. 17, N³, March 1980, pp .182-186.

DOI: $10.2514 / 3.57890$

[53] Farhat, C., Maute, K., Argrow, B., and Nikbay, M., "Shape optimization methodology for reducing the sonic boom initial pressure rise", AIAA Journal, Vol. 45, No. 5, May 2007, pp. 1007-1018.

DOI: $10.2514 / 1.2760$

[54] Jung, T. P., Starkey, R. P., Argrow, B., "Lobe balancing design method to create frozen sonic booms using aircraft components", Journal of Aircraft, Vol. 49, No. 6, November 2012, pp. 1878-1893.

DOI: 10.2514/1.C031709

[55] Cheung, S.H., Edwards, T.A., Lawrence, S.L., "Application of computational fluid dynamics to sonic boom nearand mid-field prediction”, Journal of Aircraft, Vol. 29, No. 5, September-October 1992, pp. 920-926.

DOI: $10.2514 / 3.46263$

[56] Cliff, S.E., Thomas, S.D., "Euler experiment correlations of sonic boom pressure signatures", Journal of Aircraft, Vol. 30, No. 5, September-October 1993, pp. 669-675.

DOI : $10.2514 / 3.46396$

[57] Siclari, M.J., Darden, C.M., "Euler code prediction of near-field to midfield sonic boom pressure signatures", Journal of Aircraft, Vol. 30, No. 6, November-December 1993, pp. 911-917. DOI: $10.2514 / 3.46434$

[58] Shim, I.B., Kim, J.W., Lee, D.J., "Numerical study of N-wave propagation using optimized compact finite difference schemes", AIAA Journal, Vol. 41, No. 2, February 2003, pp. 316-319.

DOI: $10.2514 / 2.1948$

[59] Rallabhandi, S.K., "Advances sonic boom prediction using the augmented Burgers equation", Journal of Aircraft, Vol. 48, No. 4, July-August 2011, pp. 1245-1253.

DOI: $10.2514 / 1 . C 031248$

[60] Yamashita, R., and Suzuki, K., "Full-field sonic boom simulation in stratified atmosphere", AIAA Journal, Vol. 54, No. 10, October 2016, pp. 3223-3231.

DOI: $10.2514 / 1 . J 054581$

[61] CIRA Working Group, Chandra, S., "COSPAR International Reference Atmosphere: 1986 (0 km to $120 \mathrm{~km}$ )", NASA Goddard Space Flight Center, MD, U.S.A., 1990.

[62] Spiegel, M.R., Mathematical handbook of formulas and tables, McGraw-Hill Inc., NY, U.S.A., 1974.

[63] Baldeschi, F., personal communication, SECAPEM, Targets and Scoring Systems, 77330 Ozoir-la-Ferrière, France, April 2007.

[64] Musso, C., personal communication, ONERA, Department DTIM (Signal Processing), 91120 Palaiseau, France, March 2016. 